NBER WORKING PAPER SERIES

\title{
FINANCING VENTURES
}

Jeremy Greenwood

Pengfei Han

Juan M. Sanchez

Working Paper 24808

http://www.nber.org/papers/w24808

\author{
NATIONAL BUREAU OF ECONOMIC RESEARCH \\ 1050 Massachusetts Avenue \\ Cambridge, MA 02138 \\ July 2018, Revised November 2021
}

Yoshiki Ando, Gian Luca Clementi, Dirk Krueger, and three referees are thanked for comments. The NSF provided financial support. Address correspondence to Juan M. Sanchez at vediense@gmail.com. The views expressed herein are those of the authors and do not necessarily reflect the views of the National Bureau of Economic Research.

NBER working papers are circulated for discussion and comment purposes. They have not been peer-reviewed or been subject to the review by the NBER Board of Directors that accompanies official NBER publications.

(C) 2018 by Jeremy Greenwood, Pengfei Han, and Juan M. Sanchez. All rights reserved. Short sections of text, not to exceed two paragraphs, may be quoted without explicit permission provided that full credit, including ( $)$ notice, is given to the source. 
Financing Ventures

Jeremy Greenwood, Pengfei Han, and Juan M. Sanchez

NBER Working Paper No. 24808

July 2018, Revised November 2021

JEL No. E13,E22,G24,L26,O16,O31,O40

\begin{abstract}
$\underline{\text { ABSTRACT }}$
The relationship between venture capital and growth is examined using an endogenous growth model incorporating dynamic contracts between entrepreneurs and venture capitalists. At each stage of financing, venture capitalists evaluate the viability of startups. If viable, venture capitalists provide funding for the next stage. The success of a project depends on the amount of funding. The model is confronted with stylized facts about venture capital: statistics by funding round concerning success rates, failure rates, investment rates, equity shares, and IPO values. The increased efficiency offered by venture capital for financing inventive startups is important for long-run growth and welfare.

Jeremy Greenwood

Department of Economics

University of Pennsylvania

Perelman Cntr for Pol Sci and Econ

133 South 36th Street

Philadelphia, PA 19104-6297

and NBER

Pengfei Han

Department of Finance

Guanghua School of Management

Peking University

Beijing 100871

P.R. China

pengfeih@sas.upenn.edu

Juan M. Sanchez

Research Department

Federal Reserve Bank of St. Louis

One Federal Reserve Bank Plaza

St. Louis, MO 63102

sanchez@stls.frb.org
\end{abstract}




\section{Introduction}

I think the development of the venture capital system has been an example of something which is a successful improvement in risk-bearing. It doesn't exactly remove the risks at the beginning, but at least creates greater rewards at a slightly later stage and therefore encourages, say, small companies to engage in technologically risky enterprises. If you like innovation, you expect 50 percent to 60 percent failure. In a sense, if you don't get that, you're not trying hard enough. Venture capital has done much more, I think, to improve efficiency than anything. Kenneth J. Arrow, The Region, December 1995

Kenneth J. Arrow highlights the role that venture capital (VC) plays in improving the efficiency of financing ventures. What is special about $\mathrm{VC}$ versus either debt or public equity financing? $\mathrm{VC}$ is often used to finance innovative startups on the technological frontier. Financing such projects is complex. First, such startups tend to have little or highly volatile cash flows. Second, these projects might have negligible collateral value, perhaps just an idea. Property rights may not be firmly established. Third, there may be considerable uncertainty about the worth of the idea underlying the startup, with insiders knowing much more than outsiders. Fourth, since the revenues and expenses of such projects are often unclear, there is considerable scope for malfeasance. In their infancy these types of startups may not even have good accounting systems.

The first two points make it difficult to use debt finance, which requires making regular interest payments and having assets to seize upon default. The first and third points speak against public equity finance. In the startup stage these firms are too small for an initial public offering, which requires considerable public disclosures. Plus, the private information aspects of such startups makes it difficult for the owners (insiders) to reap from investors (outsiders) the project's worth. The fourth point also weighs against debt and public equity finance due to the difficulties of monitoring this type of startup.

$\mathrm{VC}$ overcomes some of the difficulties of debt and public equity finance. Entrepreneurs and venture capitalists sign a contract that stipulates the amount of $\mathrm{VC}$ funding and the share each party will receive of either an IPO or a merger and acquisition (M\&A) if the startup is successful. This avoids the cash-flow problem faced by debt financing. In a sense then, VC financing resembles public equity financing. Before signing a contract, venture capitalists evaluate a startup. Since venture capitalists are highly skilled this reduces the

private information problem. Additionally, funding is sequenced across multiple rounds. At each round the venture capitalists evaluate projects and inject cash according to their assessment, which reduces the information problem. Venture capitalists spend a lot of time 
monitoring projects. Together with the fact that the payoffs from a venture occur only upon success, this operates to reduce the moral hazard problem. Last, venture capitalists play an active part in launching startups. This mentoring aspect of VC is largely absent in debt and public equity finance.

\subsection{Venture Capital, Innovation, and Economic Growth}

To date no effort has been devoted in macroeconomics to incorporating VC into an endogenous growth model with dynamic contracts. Providing such a model is the main contribution of this paper. This contribution is crucial for understanding how VC works. It can be used to answer questions such as: (i) What is the role of different rounds in the VC financing process? (ii) What limits the size of investment in a startup? (iii) How does the ability of venture capitalists to select projects, monitor them to prevent fraud, and develop new ideas affect the likelihood of a successful startup?

Once the model is developed and validated with U.S. data, it can be exploited to provide new answers to long-standing questions such as: (i) What are the implications of VC for growth and welfare? (ii) How does the taxation of corporate profits affect growth? (iii) What accounts for differences in the growth rates between continental Europe and the United States?

The importance of venture capital in the U.S. economy has skyrocketed over the past 50 years. Investment by venture capitalists was roughly $\$ 303$ million in 1970 . This soared to $\$ 54$ billion by 2015 (both numbers are in $\$ 2009$ ). The rise in venture capital financing is shown in the right-hand-side panel of Figure 1. While the share of VC funding in total investment is still relatively small, around 2 percent in 2015, its punch far exceeds its weight. The fraction of public firms that have been backed at some time by venture capitalists is now around 20 percent, compared with just 4 percent in 1970-see the left-hand-side panel of Figure 1. (See the Empirical Appendix-Section 11-for the sources of all data used in the paper.) Such firms presently account for about 20 percent of market capitalization. The capitalization line lies below the fraction-of-firms line because VC-backed companies tend to be more recent entrants that are younger and smaller in size, whereas their nonVC-backed counterparts tend to be established incumbents. Today, VC-backed firms are significant players in job creation and technological innovation. Public firms that were once backed by venture capitalists currently make up a significant fraction of employment and an even larger share of R\&D spending, as opposed to virtually nothing in 1970, as the lefthand-side panel of Figure 2 makes clear. The right-hand side of the figure displays their 

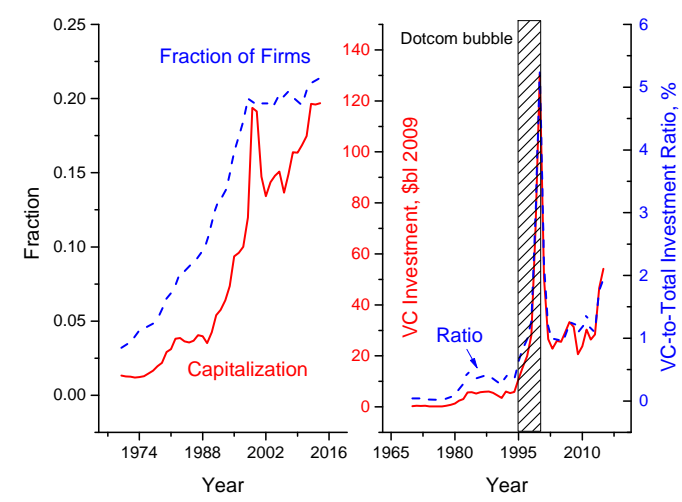

Figure 1: The rise of venture capital, 1970 to 2015. The right-hand-side panel shows investment by venture capitalists. The left-hand-side panel plots both the fraction of public firms financed by venture capitalists and the share of VC-backed public firms in market capitalization.

enormous contribution to the generation of patents, both in raw and quality-adjusted terms. The employment share of VC-backed firms is far less than the R\&D (and patents) share. This is because VC-backed companies are more R\&D intensive than their non-VC-backed counterparts. For instance, Google (a VC-backed company) has far fewer employees than General Motors (a non-VC-backed company), but Google invests a lot more in R\&D than General Motors.

The VC industry has been an incubator of numerous technological giants in the information and communication technology sector as well as the biotechnology sector, plus an array of star innovators in the service industry. Former VC-backed firms are household names. Figure 3 shows the top 30 VC-backed public companies by market capitalization. Figure 4 plots the relative significance of the words "banks" and "venture capital," as reflected by their usage in English language books. As shown, the term venture capital was virtually unused in 1930. The relative significance of venture capital vis-à-vis banks has increased considerably since then.

How is VC linked to firm growth and technological innovation in the United States? To investigate this question, some regression analysis is presented in Section 11 of the Empirical Appendix. The upshot of the analysis is this: Following an IPO, VC-backed public companies have $\mathrm{R} \& \mathrm{D}$-to-sales ratios that are 5.2 percentage points higher than their non-VC-backed counterparts. Subsequent to an IPO, they also grow faster in terms of employment and sales; 4.9 and 7.0 percentage points higher, respectively. VC-backed companies are embraced as "golden geese" by the investors. They are valued 37 percent higher than their non-VC-backed 

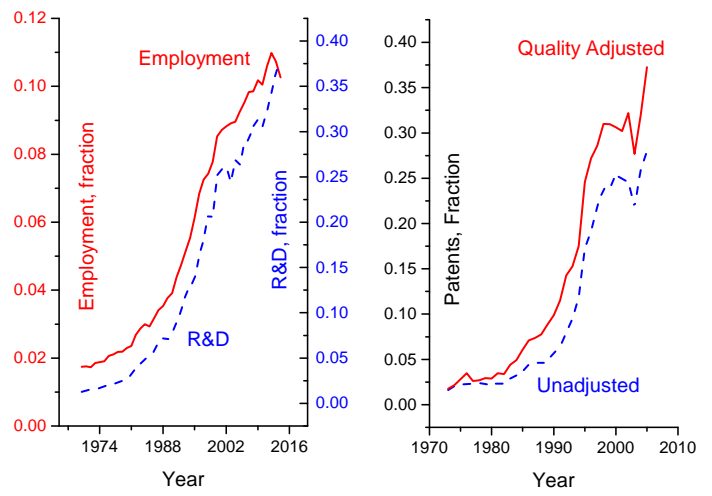

Figure 2: The share of VC-backed firms in employment, R\&D spending, and patents. The data in the left-hand-side panel are from 1970 to 2014, while that in the right-hand-side panel spans 1973 to 2005.

\begin{tabular}{|c|c|c|c|c|c|}
\hline \multicolumn{6}{|c|}{ Top 30 VC-Backed Companies } \\
\hline 1 & tásen & 11 & (Q) nVIDIA & 21 & $\underset{U B E R}{9}$ \\
\hline 2 & amazon & 12 & Sun & 22 & Ccts \\
\hline 3 & In:Microsoft & 13 & O GILEAd & 23 & stryker \\
\hline 4 & Alphabet & 14 & AMGEN & 24 & Qairbnb \\
\hline 5 & faceboook & 15 & AMDA & 25 & InT்uıт் \\
\hline 6 & $r$ & 16 & servicenow & 26 & fiserv. \\
\hline 7 & $\begin{array}{l}\text { "W1.111. } \\
\text { cisco }\end{array}$ & 17 & STARQucks & 27 & ebay \\
\hline 8 & NETFLIX & 18 & 口 Square & 28 & 23 SnapChat \\
\hline 9 & ORACLE & 19 & Genentech & 29 & Buvion \\
\hline 10 & $\rightarrow$ & 20 & INTUITIVE & 30 & $\underset{\text { COMPAC }}{\mathrm{C}_{\mathrm{A}}}$ \\
\hline
\end{tabular}

Figure 3: The logos of the top 30 VC-backed companies sorted by their highest market capitalization as of 2020. These companies are identified by matching firm names in VentureXpert and CompuStat. 


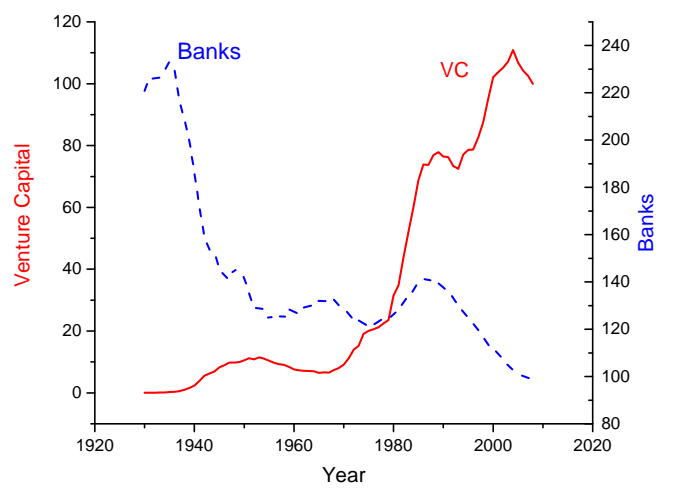

Figure 4: Banks and venture capital, 1930-2008. The figure plots the use of the words "banks" and "venture capital," relative to all words in English language books, using the Google Ngram Viewer. For each series, the value in 2008 is normalized to 100.

counterparts around the time of an IPO. In addition, VC is a potent apparatus for financing technological innovation. A 10 percent increase in VC funding is positively associated with a 7.5 percent rise in (quality-adjusted) patenting activity by firms. Those industries where VC funding is high tend to have bigger levels of employment and sales growth.

Turn now to some cross-country evidence. At the country level, VC investment appears to be positively linked with economic growth. Figure 5 illustrates the conditional relationship between the VC-investment-to-GDP ratio and the growth rate of real GDP per capita for a sample of 40 countries. The vertical axis is the median growth rate of per capital real GDP in each country for 2005 to 2014, residualized against the following control variables: the initial levels of real GDP per capita, a human capital index, and the ratio of domestic private credit to GDP. The horizontal axis is the median VC-investment-to-GDP ratio (in natural logarithm) between 2001 and 2005 for a country. ${ }^{1}$ As depicted in Figure 5, a higher VC-investment-to-GDP ratio in a country predicts faster economic growth in the subsequent decade. This relationship is statistically significant at the 1 percent level-see the Empirical Appendix.

\subsection{What's done here}

To address the importance of VC in the U.S. economy, an endogenous growth model where VC finances innovation is developed. At the heart of the growth model is a dynamic contract between an entrepreneur and a venture capitalist. The venture capitalist invests in the

\footnotetext{
${ }^{1}$ In light of the remarkable volitility of VC investment, the median value between 2001 and 2005 is used.
} 


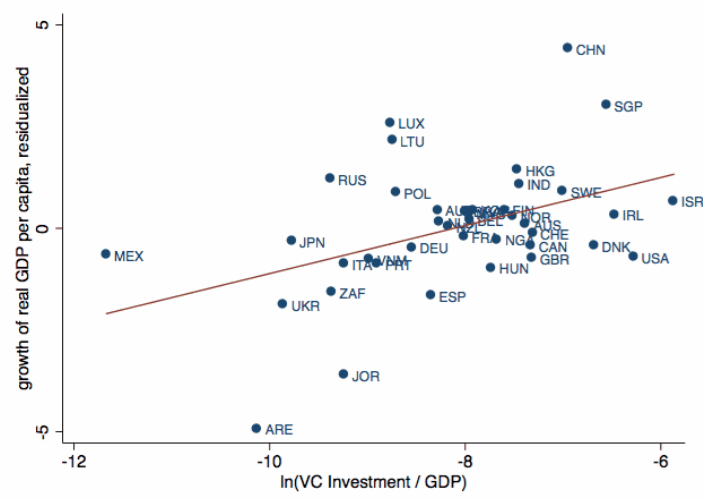

Figure 5: The conditional cross-country relationship between economic growth and VC investment, 2005-2014.

entrepreneur's startup as an active participant. The venture capitalist provides seed money for initial research. The project then enters a funding-round cycle. At the beginning of each funding round the venture capitalist evaluates the worthiness of the project. Those projects that pass the evaluation are given funds for development. The contract is designed so that it is not in the entrepreneur's interest to divert funds away from their intended purpose. The venture capitalist can imperfectly monitor, at a cost, the entrepreneur's use of funds, which helps to ensure incentive compatibility. Those ventures that are successful during a funding round are floated on the stock market (or go through a merger and acquisition).

The contract specifies for each funding round the evaluation strategy to gauge the project's worthiness, the amount of $\mathrm{VC}$ invested in development, the level of monitoring to avoid malfeasance, and the shares of each party in the proceeds from a potential IPO. The agreement is optimal, from both the entrepreneur's and venture capitalist's perspectives, given the economic environment in which the two parties work. The predicted features of the contract are compared with some stylized facts about venture capital: (i) the success and failure rates by funding round, (ii) investment by funding round, (iii) the value of an IPO by duration of the incubation period, and (iv) the venture capitalist's share of equity by funding round. The availability of $\mathrm{VC}$ funding-round data gives rise to one of the rare instances where the predictions of dynamic contract theory can be confronted with data.

Despite the importance of VC, the preponderance of U.S. firms are not financed through this channel. So, the analysis includes a traditional sector that produces the majority of output using capital that can be thought of as being financed through regular banks. It is assumed that these firms are not the engines of innovation. Hurst and Pugsley (2011) show that the great majority of new businesses do not plan to innovate or grow. Only roughly 
10 percent of all new businesses reported that they plan to develop proprietary technology, processes, or procedures in the future (Table 8), and by the fourth year of their life, only 2.7 percent have or are applying for a patent (Table 6). Some additional evidence justifying the notion that a disproportionate share of innovation is done by VC-backed firms is presented in Section 2.6.

Over time the financial sector of the economy has become more efficient, just like the non-financial sector. VC is an example of technological advancement in the financial sector. The impact of finance on development has long interested economists. To study the impact of financial development on the economy, a thought experiment is conducted: The efficiency of evaluation, development, and monitoring processes are all varied in an equiproportional manner from the calibrated equilibrium. Economic growth and welfare move upward in lockstep with technological advancement in the financial sector.

How does the tax code affect VC activity? The key participants in a VC partnership receive the majority of their compensation in the form of stock options and convertible equity. As such, in the United States they are subject primarily to capital gains taxation. The analysis examines how innovative activity is affected by the capital gains tax rate. The higher the rate of capital gains taxation, the greater the incentive of entrepreneurs to secrete investment funds into nontaxable forms of consumption. This will discourage the VC from providing funding because it increases the severity of the moral hazard problem associated with VC investment. The rates of taxation on VC-funded startups vary widely across countries, and with it so do the levels of VC activity. The calibrated model matches this cross-country relationship. The impact that taxes on startups have on growth is then examined. Economic growth would fall from 1.78 to 1.62 percent, if VC-funded startups in the United States are taxed at the German rate. This leads to a large drop in welfare. To highlight the role that VC and taxation may play in generating differences in growth across countries, a comparison is undertaken between France and the United States. Compared with France, faster economic growth in the United States is primarily attributed to the better value-added services provided by venture capitalists to develop startups, as well as the lower rate of startup taxation.

\subsection{Literature Review}

Dynamic contract frameworks that focus on firms, and VC in particular, are rare. Bergemann and Hege (1998), Clementi and Hopenhayn (2006), Cole, Greenwood, and Sanchez (2016), Cooley, Marimon, and Quadrini (2004), and Smith and Wang (2006) develop contracting 
structures that share some similarities with the one presented here. Clementi and Hopenhayn (2006), Cooley, Marimon, and Quadrini (2004), and Smith and Wang (2016) model longterm credit relationships between entrepreneurs and lenders. Lenders cannot monitor the borrower. The focus of Cole, Greenwood, and Sanchez (2016) is on the efficaciousness of financial markets for technology adoption across countries. These analyses stress the efficiency of long-term contracts. Since they do not focus on VC, they do not formulate the incubation period where a lender supplies funding for research and development while evaluating the worthiness of the startup and monitoring the use of funds. Therefore, none of the above papers compares the predictions of their models with the VC process in the United States. And none of them examines how innovative activity is affected by the rate of capital gains taxation. The current analysis is also done within the context of an endogenous growth model, unlike any of the above work. A new entrepreneur decides how far to push his productivity relative to the frontier. The position of the frontier in the current work is determined by a classic Romer-(1986)-type externality.

In Bergemann and Hege (1998) a venture capitalist also learns about a project's type, good or bad, over time. Their research yields some valuable insights about how to model the $\mathrm{VC}$ staging process. Unlike the current analysis, however, a venture capitalist cannot invest in evaluating a project in each funding round to learn about its type, good or bad. As noted by Lerner (1998), the Bergemann and Hege (1998) analysis implies that a venture capitalist's belief that a startup is bad must rise over time as the project fails to go to market. This force leads to investment declining over time. An important real-world feature about stage financing is that it permits a venture capitalist to evaluate and produce information during a funding round about a project's worth. While this evaluation process is costly, it allows the venture capitalist to cut bad projects more speedily, ensuring, to quote Lerner (1998, p. 737), that the "lemons ripen faster than plums." By investing in this additional information acquisition repeatedly across funding rounds (instead of performing a one-shot evaluation up front), the odds that a project is good can rise over funding rounds. This works to generate an upward-sloping investment profile by funding round, something the Bergemann and Hege (1998) framework does not yield. So, it seems important to include some form of an evaluation process in a model of $\mathrm{VC}$, as is done in the current analysis. While the Bergemann and Hege (1998) model shares features with the current analysis, their structure is linear in nature. While this facilitates analytical results, it renders corner solutions, which makes the framework impossible to match the U.S. data. (For example, in their setting, investment is either zero or at its assumed upper bound, while monitoring is only done toward the end of contract.) Also since their analysis is partial equilibrium, it is 
silent about the impact of $\mathrm{VC}$ on the performance of the economy at large.

Last, a tractable, stylized Schumpeterian model of $\mathrm{VC}$ that has analytical solutions is developed by Opp (2019). While his model captures the risk properties and boom-bust cycle of $\mathrm{VC}$, the analysis is oriented toward finance and does not take a dynamic contract perspective. In his framework, entrepreneurs do not choose how far to launch their endeavor ahead of the pack. Compared with alternative modeling approaches, a dynamic contract theory of VC is particularly well suited to decompose VC's contributions into specific channels (evaluating, developing, and monitoring) and assess their relative importance. As taken up later, such a decomposition exercise sheds light on why the $\mathrm{VC}$ system is prosperous in the United States, whereas it is ailing in continental Europe.

\section{$2 \quad$ The Setting}

At the center of the analysis is the interplay between an entrepreneur and a venture capitalist, which is governed by an incentive-compatible financial contract. Entrepreneurs have ideas, but no money, while venture capitalists have expertise and money, but no ideas. ${ }^{2}$ Each period new entrepreneurs bring ideas of their choosing to a venture capitalist to obtain funding. The parties sign a partnership agreement that has finite duration. Most VC enterprises are operated as partnerships.

At the time the contract is signed, the venture capitalist provides seed money to research initially the idea. After this initial research is finished, the project enters a funding-round cycle that may last for many periods. Some ideas brought by entrepreneurs to the venture capitalist are good, others are bad. Only a good idea has a payoff, and even then this might not happen. Neither party knows whether an idea is good or bad. So, at the beginning of each funding round the venture capitalist evaluates the project at a cost in an attempt to detect whether the venture is bad. Bad projects are terminated. Projects that aren't known to be bad are given development money. The probability of success within a funding round is an increasing function of the level of investment in development undertaken by the entrepreneur. How much of the money the entrepreneur actually uses for development is private information. The venture capitalist can imperfectly monitor development investment at a cost in an attempt to detect any malfeasance. When malfeasance is detected, the venture capitalist drops the venture.

\footnotetext{
${ }^{2}$ For work that emphasizes the role of borrowing constraints and savings in the development process, see the survey paper by Buera, Kaboski, and Shin (2011). A recent example of this work is Cavalcanti et al (2021).
} 


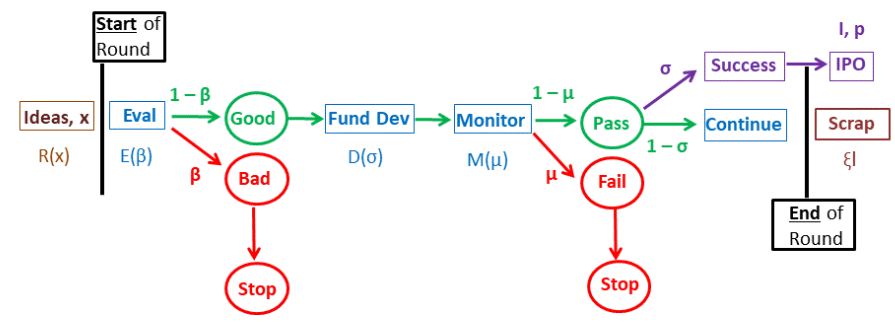

Figure 6: The timing of events within a typical funding round. The research underlying the idea occurs at the very beginning of the funding cycle, or round 0 , and is shown to the left of generic funding round. A surviving project can be sold for scrap at the end of the contract, or at the end of round $T$, as shown to the right of the typical funding round.

If successful, the project will be floated on the stock market or sold to another firm, which yields a reward that will be a function of the idea's type. The reward is split between the entrepreneur and venture capitalist as specified by the partnership agreement. Any profits from floating a VC-funded enterprise are subject to capital gains taxation. All revenue from capital gains taxation is rebated back to the populace in lump-sum transfer payments. If the project is not successful, then it enters another funding round, provided the contract has not expired, and the funding cycle goes on. At the time a contract expires, an unsuccessful surviving project can be sold by the venture capitalist for scrap. The timing of events within a generic funding round is shown in Figure 6 .

The analysis focuses on a balanced-growth path. The aggregate level of productivity in the $\mathrm{VC}$ sector is denoted by $\mathbf{x}$, which represents the aggregate state of the economy. Aggregate productivity will be a weighted average of VC-backed firm-level productivities, which differ by a startup's vintage. Along a balanced-growth path, $\mathbf{x}$ will grow at the gross rate $g_{\mathbf{x}}>1$ so that

$$
\mathrm{x}^{\prime}=\mathrm{g}_{\mathrm{x}} \mathrm{x}
$$

The gross growth rate of aggregate productivity, $\mathbf{g}_{\mathbf{x}}$, is an endogenous variable in equilibrium. It will be a function of the efficiency of the VC system. The gross growth rate in wages, $\mathbf{g}_{w}$, will be a function of the growth rate of aggregate productivity, $\mathbf{g}_{\mathbf{x}}$. The discussion now 
proceeds by detailing the stages portrayed in Figure 6 .

\subsection{The Research Stage-Starting a New Venture}

Each period an inflow of new entrepreneurs in the amount $\mathfrak{e}$ approach venture capitalists to obtain funding for their ideas. An entrepreneur incurs an opportunity cost in the amount $w \mathfrak{o}$ to run a project, where $w$ is the wage rate for labor. The component $\mathfrak{o}$ of this cost is distributed across potential entrepreneurs according to the non-normalized distribution function, $O(\mathfrak{o})$. This distribution function $O(\mathfrak{o})$ is assumed to be Pareto so that

$$
O(\mathfrak{o})=1-(v / \mathfrak{o})^{\nu}, \text { with } \nu, v>0
$$

Only those potential entrepreneurs who expect the payoff from a startup to exceed their opportunity cost, wo, will approach a venture capitalist for funding. This criterion determines the number entrepreneurs, $\mathfrak{e}$, that approach venture capitalists for funding, which is formalized in Section 4.1.

A new entrepreneur is free to choose the type of startup, $x$, that he wants to develop. At the time of entry entrepreneurs have no personal knowledge about whether their idea is good or bad. Hence they all select same type of startup, which differs from what past entrants chose. When deciding on the project, the entrepreneur picks $x$ subject to a research cost function of the form

$$
i=R\left(\frac{x}{\mathbf{x}}\right)=w\left(\frac{x}{\mathbf{x}}\right)^{\iota} / \chi_{R},
$$

where $i \geq 0$ is the initial investment in researching the project. The entrepreneur can choose how far ahead the productivity of his firm, $x$, is from the average level of productivity in the VC sector, $\mathbf{x}$. The more ambitious he is, or the higher $x$ is relative to $\mathbf{x}$, the greater will be the research cost, which rises in convex fashion. The cost of research, $R(x / \mathbf{x})$, rises with the current level of wages, $w$, which will be a function of the aggregate state of the economy, $\mathbf{x}$. One can think about these costs as either being directly in terms of labor, $R(x / \mathbf{x}) / w$, or indirectly in terms of goods, $R(x / \mathbf{x})$, which are produced using labor. Both types of costs rise with the wage rate; at a theoretical level it doesn't matter. ${ }^{3}$ The productivity of the research is governed by $\chi_{R}$. This structure provides a mechanism for endogenous growth in the model.

\footnotetext{
${ }^{3}$ Footnote 13 discusses this in more detail.
} 


\subsection{The Evaluation Stage}

Out of the pool of new entrepreneurs, the fraction $\rho$ have good ideas, implying that the fraction $1-\rho$ have bad ones. The venture capitalist can potentially discover a bad project by evaluating it. Assume that the venture capitalist can detect within each funding round a bad project with probability $\beta$, according to the cost function, $E(\beta ; \mathbf{x})$, where $E$ is an increasing, convex function in $\beta$. Specifically,

$$
E(\beta ; \mathbf{x})=w\left(\frac{1}{1-\beta}-1\right) \beta / \chi_{E} .
$$

Note that the marginal cost of evaluating starts at zero when $\beta=0$ and goes to infinity as $\beta$ approaches 1 . The cost of evaluating rises with the level of wages, $w$. In equilibrium wages will depend on the aggregate state of the economy, $\mathbf{x}$, which explains the form of the left-hand side of the equation. Again, these costs can be thought of as either being in terms of labor or in terms of goods. Think about $\chi_{E}$ as capturing the efficiency of investment in evaluation. Projects that are detected to be bad are thrown out. The purging of bad projects at the start of the first funding round, before any investment has occurred, can be thought of as the venture capitalist selecting which projects to finance.

\subsection{The Development Stage}

Ventures that pass the evaluation stage are given development funding. The level of funding depends upon the common prior (held by the entrepreneur and venture capitalist) that the project is good, which evolves across funding rounds. The odds of success during a funding round depend on the entrepreneur's investment in development. In particular, a probability of success (conditional upon the project not being evaluated as bad), $\sigma$, can be secured by undertaking development investment in the amount $D(\sigma ; \mathbf{x})$, where $D$ is an increasing, convex function in $\sigma$. The development cost function $D(\sigma ; \mathbf{x})$ is given the form

$$
D(\sigma ; \mathbf{x})=w\left(\frac{1}{1-\sigma}-1\right) \sigma / \chi_{D} .
$$

The development cost function $D(\sigma ; \mathbf{x})$ has a similar form to that for $E(\beta ; \mathbf{x})$.

There is also a fixed cost, $\phi_{t}$, connected with developing a startup project in round $t$. One would expect these costs to increase over the startup phase as the project is brought to fruition. These fixed cost also rise in tandem with the level of wages in the economy. In 
particular,

$$
\phi_{t}=w_{1} \mathbf{g}_{w}^{t-1} \phi(t)
$$

where $w_{1}$ represents the round- 1 wage rate and $\mathbf{g}_{w}>1$ is the gross growth rate in wages (which will be a function of $\mathbf{g}_{\mathbf{x}}$ ). Additionally, the fixed cost changes by the round of the project, as reflected by the function $\phi(t)$. The inclusion of these fixed costs is important for controlling the profitability of $\mathrm{VC}$ activity. When profits are large it is easy to structure a contract between entrepreneurs and venture capitalists that will create the correct incentives for the former. The fixed costs determine how binding the incentive constraint in the contract will be. The shape of the function $\phi(t)$ will be parameterized using a polynomial that is disciplined by U.S. VC funding-round data.

\subsection{The Monitoring Stage}

The venture capitalist provides in a funding round the amount $D(\sigma ; \mathbf{x})$ for development. The entrepreneur may decide to spend some smaller amount $D(\widetilde{\sigma} ; \mathbf{x}) \leq D(\sigma ; \mathbf{x})$ and siphon off the difference, $D(\sigma ; \mathbf{x})-D(\widetilde{\sigma} ; \mathbf{x})$. The entrepreneur uses the difference in funds for his own consumption-these funds cannot be secreted for investment/savings. By diverting funds, the entrepreneur reduces the odds of success in the current funding round; i.e., $\widetilde{\sigma} \leq \sigma$. The venture capitalist can dissuade this fraud by engaging in monitoring. Assume that the venture capitalist can pick the odds $\mu$ of detecting fraud in a venture during round $t$ according to the strictly increasing, convex cost function, $M_{t}(\mu ; \mathbf{x})$, where

$$
M_{t}(\mu ; \mathbf{x})=w_{1} \mathbf{g}_{w}^{t-1}\left(\frac{1}{1-\mu}-1\right) \mu / \chi_{M, t} .
$$

This flexible monitoring technology is borrowed from Greenwood, Sanchez, and Wang (2010). ${ }^{4}$ It differs from the more traditional form used in costly-state-verification models in two key ways. First, the outcome of monitoring is random. Second, this form implies that the more the venture capitalist invests in auditing, the higher the odds that he will detect any irregularities. The cost of monitoring rises with wages in the economy. Additionally, monitoring costs change in each round of the project, as reflected by the term $\chi_{M, t}$; again, $\chi_{M, t}$ represents the productivity of this auditing process in round $t$. Presumably, as the venture capitalist becomes more familiar with the project, $\chi_{M, t}$ will rise with $t$. This feature implies that the incentive problem will become less severe over time and helps to generate an upward-sloping funding profile. A polynomial for $\chi_{M, t}$ will be fit to the U.S. VC funding-round data.

\footnotetext{
${ }^{4}$ The evaluation and development functions are also motivated by this form.
} 
Moral hazard has been a cornerstone in the financial literature. Townsend (1979) and Williamson (1986) use it to motivate the form of debt contracts. Greenwood, Sanchez, and Wang (2013) build on their frameworks to explain cross-country differences in income and interest-rate spreads between lending and saving. Paulson, Townsend, and Karaivanov (2006) estimate a structural model of entrepreneurship and find that the dominant source of credit market imperfection is moral hazard (as opposed to limited liability). According to Bernstein, Giroud, and Townsend (2016) and Lerner (1998), venture capitalists devote a considerable amount of time to monitoring their investments-this fact is returned to in Section 5 .

Evidence of financial malfeasance in startups is abundant. It takes many forms. Funds may be diverted for private jets for travel, multimillion dollar launch parties, the use of private boxes at sports events, and luxury vacations, etc, as exemplified by this quote:

This week, Elvis Costello will play at a bash hosted by AskJeeves, while a collection of works by Picasso never before shown in the United States will be shown at a much more upscale Hewlett-Packard-sponsored party. Such decadent affairs are in keeping with current party expectations. A Respond.com party late last year featured performers from Cirque du Soleil. Source: Cave, Damien, "Dot-com party madness." Salon.com (April 25, 2000).

Another example is WeWork started by Adam Neumann and backed by SoftBank, a large VC company. WeWork offered flexible office space for businesses. After filing registration papers with the Security and Exchange Commission (SEC), it spiraled down in just over 6 weeks starting in August 2019 from being valued at $\$ 47$ billion to talk of bankruptcy. Neumann spent lavishly: He purchased more than 5 homes, drank $\$ 149$ bottles of tequila, took large personal loans from the firm at below-market interest rates, charged the firm $\$ 5.9$ million in licensing fees to use his trademark "We" in its name, bought a $\$ 60$ million jet for the company and flew around the world, made millions by leasing property he owned back to the business (a conflict of interest), and diverted company funds to pet projects, such as $\$ 14$ million into surfing wave pools.

Other times outright fraud is involved. A famous example is the case of the now defunct Theranos, a health tech startup founded by Elizabeth Holmes, who was charged with massive fraud in 2018. 


\subsection{The Success Stage-Floated Firms}

A startup of type $x$ turns into a going concern with productivity $x$, if successful. A successful VC-backed firm produces output, $o$, according to the production process

$$
o=x^{\zeta} k^{\kappa} l^{\lambda}, \text { with } \zeta+\kappa+\lambda=1 \text {, }
$$

where $k$ and $l$ are the amounts of capital and labor used in production. This structure results in the firm earning pure profits that are linear in its productivity, $x$. The lure of capturing these profits is what motivates entrepreneurs and venture capitalists. Labor is hired at the wage rate, $w$, and capital at the rental rate, $r$. The firm's per period net surplus is

$$
\begin{aligned}
S(x ; \mathbf{x}) & =\max _{k, l}\left\{x^{\zeta} k^{\kappa} l^{\lambda}-r k-w l\right\} \\
& =x(1-\kappa-\lambda)\left[\left(\frac{\kappa}{r}\right)^{\kappa}\left(\frac{\lambda}{w}\right)^{\lambda}\right]^{1 / \zeta} .
\end{aligned}
$$

Clearly, as wages rise, which will be a function of the aggregate state of the economy, $\mathbf{x}$, net takings will shrink for a given level of the firm's productivity, $x$. Operating firms last stochastically in accordance with the time-invariant survival rate, $\mathfrak{s}$.

A successful VC-backed project is sold for $I(x ; \mathbf{x})$, either through an IPO or an M\&A, just before production starts. The (gross) reward for a successful IPO is

$$
I(x ; \mathbf{x})=\sum_{t=1}^{\infty}(\mathfrak{s} \delta)^{t-1} S\left(x ; \mathbf{g}_{\mathbf{x}}^{t-1} \mathbf{x}\right)
$$

where $\delta$ is the market discount factor. If the startup is successful, the entrepreneur must pay the venture capitalist the amount $p$. So the entrepreneur will reap the amount $I(x ; \mathbf{x})-p$, which is taxed at the capital gains rate, $\tau$. If a project is not successful, it moves back to the evaluation stage, assuming that the contract has not expired. An ongoing project that is unsuccessful by the time the contract expires at end of round $T$ can be sold by the venture capitalist for scrap value. The scrap value for a project in the current period is $\xi I(x ; \mathbf{x})$, where $0<\xi<1$.

\subsection{Non-VC-Funded Firms}

Most firms are not funded by venture capitalists. To capture this, suppose there are always $\mathfrak{m}$ firms operating that were not funded by VC. All firms in the non-VC-funded sector are the 
same. These non-VC-funded firms produce using a production function that is identical to a VC-funded firm with one exception: Their productivity differs. Specifically, they produce in line with

$$
o=z^{\zeta} k^{\kappa} l^{\lambda}, \text { with } \zeta+\kappa+\lambda=1,
$$

where $z$ represents their productivity. Suppose that

$$
z=\omega \mathbf{x}, \text { with } \omega<1
$$

Thus, firms in the non-VC-funded segment of the economy are on average less productive than the ones in the VC segment. Recall that $\mathbf{x}$ is the average productivity of VC-funded firms. Hence, non-VC-funded firms are dragged along by VC-funded firms. Non-VC-funded firms raise their capital via traditional financial intermediaries.

The assumption that non-VC-funded firms do not innovate technologically is probably not too far from reality. Again, the great majority of new businesses do not to plan to innovate or grow, as discussed by Hurst and Pugsley (2011). Electricians, landscapers, and restaurants exemplify such firms. The odds of becoming a successful inventive start-up are much higher for VC-funded start-ups than for non-VC-funded ones. Akcigit et al (2019) calculate from the U.S. data that 26 percent of VC-funded startups make it into the top 10 percent of all startups ten years after receiving their first VC funding. This compares with only 3.5 percent of non-VC-funded startups. Furthermore, even when making it into the top 10 percent, the patenting levels of non-VC-funded startups are only 20 percent of VC-funded ones. Startups that lie in the bottom 90 percent of firms do relatively little patenting. Their patenting levels are only 4.3 percent of the VC-funded firms that make it into the top 10 percent. In fact, Akcigit et al (2019) estimate that such firms contribute negatively to the growth in aggregate TFP; specifically, they have TFP levels 10 years after startup that are below aggregate TFP at the time of their inception (ten years previously). There is relatively little technological innovation in large swaths of the economy, such as food (NAICS code: 311), beverage and tobacco products (NAICS code: 312), paper manufacturing (NAICS code: 322), and printing and related support activities (NAICS code: 323), inter alia. ${ }^{5}$ Additionally incumbents, even in technologically innovative sectors, rely on VC-funded startups. They acquire ideas from startups by buying patents and striking licensing agreements, and increasingly through M\&A-as well as just osmosis. So again, modeling growth as originating from VC-funded

${ }^{5}$ To be more specific, the number of patents per 1,000 employees is 0.65 in the food industry, 1.71 in the beverage and tobacco products industry, and 2.14 in the paper manufacturing, printing and related support activities sector. Source: Economics and Statistics Administration, U.S. Patent and Trademark Office. 2016. "Intellectual Property and the U.S. Economy: 2016 Update" (Table A1, p. 33). 
startups, while a simplification, is not a great departure from the real world.

\section{The Financial Contract}

The financial contract between the entrepreneur and the venture capitalist is cast now. VC is a competitive industry so the entrepreneur shops around to secure the financial contract with the best terms. Venture capitalists cover the cost of research, evaluation, development, and monitoring. They raise the money to do this from savers, to whom they promise a gross rate of return of $1 / \delta$. There are no profits on $\mathrm{VC}$ activity in equilibrium. The profits that accrue to the entrepreneur are subject to the rate of capital gains taxation, $\tau$. The analysis presumes that there is a maximum of $T$ rounds of potential funding.

The timing of events for the contract is shown in Figure 6. The research for the idea is done at the start of the funding-round cycle or in round zero. At the beginning of a generic funding round, the venture capitalist evaluates projects and purges the ones that are found to be bad. Good projects are then given an injection of cash for development. The venture capitalist monitors the use of these funds. If malfeasance is detected, the project is terminated. Some projects will be successful. These are floated in the next period on the stock market. The unsuccessful projects then start another funding round, assuming the number of funding rounds doesn't exceed $T$. At the end of round $T$, any unsuccessful surviving projects can be sold by the venture capitalist for scrap.

The assumption that the venture capital industry is competitive is certainly true today, albeit not historically speaking. According to the National Venture Capital Association, in 2016 there were $898 \mathrm{VC}$ organizations with average assets under management of $\$ 243.6$ million. Among these VC organizations, only 68 managed $\$ 1$ billion or more. In contrast, 334 VC organizations managed $\$ 50$ million or less. The share of total assets under management is 14.7 percent for the five largest U.S. VC firms and 2.3 percent for the five largest U.S. VC funds. By comparison, the five largest U.S. banks control 44.6 percent of the industry's total assets.

The assumption of a fixed $T$ is not so severe. In reality VC contracts are of short duration. This puts pressure on the parties involved to work together to launch the project in a timely manner. VC contracts are also difficult to renegotiate, since parties may want to quit with a buy out or to bring in new parties. In the analysis, a venture capitalist can effectively terminate a contract before $T$ by cutting off any further investment. As will be been, in the U.S. data the odds of a successful startup fall with the length of incubation period. Since the

odds of success in the U.S. data are very low at the chosen $T$ in the quantitative analysis, it 


\begin{tabular}{|c|c|c|}
\hline$\overline{\text { Round }}$ & Number good & Number bad \\
\hline 1 & $\rho$ & $(1-\rho)\left(1-\beta_{1}\right)$ \\
\hline 2 & $\rho\left(1-\sigma_{1}\right)$ & $(1-\rho)\left(1-\beta_{1}\right)\left(1-\beta_{2}\right)$ \\
\hline 3 & $\rho\left(1-\sigma_{1}\right)\left(1-\sigma_{2}\right)$ & $(1-\rho)\left(1-\beta_{1}\right)\left(1-\beta_{2}\right)\left(1-\beta_{3}\right)$ \\
\hline$\vdots$ & $\vdots$ & \\
\hline$t$ & $\rho \prod_{j=1}^{t-1}\left(1-\sigma_{j}\right)$ & $(1-\rho) \Pi_{j=1}^{t}\left(1-\beta_{j}\right)$ \\
\hline
\end{tabular}

Table 1: The number of good and bad projects by funding round assuming that the venture capitalist starts with a unit mass of ventures.

is unlikely to observe an IPO or M\&A after $T$. In light of this, the assumption of a fixed $T$ is not very biting. ${ }^{6}$ Additionally, the fact that a project can be sold for scrap value captures somewhat the value of a renegotiated new contract. See Spear and Wang (2005) for an example of a contract problem with endogenous duration.

\subsection{The Evolution of Beliefs about Project Type}

Let $\beta_{t}$ represent the odds of detecting a bad project in round $t$ and $\sigma_{t}$ denote the probability of success for a good project. Now suppose that a unit measure of new entrepreneurs approaches a venture capitalist for funding. As the funding rounds progress, the numbers of good and bad projects will evolve as shown in Table 1. For example, of the entrepreneurs initially applying for funding, the number $\rho$ will have good projects and $1-\rho$ will have bad ones. In round 1 the venture capitalist will evaluate the applicants and eliminate $(1-\rho) \beta_{1}$ bad projects, so that $(1-\rho)\left(1-\beta_{1}\right)$ bad ones will still remain. Of the good projects, the number $\rho \sigma_{1}$ will be successful. So, at the beginning of the second round there will be $\rho\left(1-\sigma_{1}\right)$ good projects in the pool. After the second-round evaluation, $(1-\rho)\left(1-\beta_{1}\right)\left(1-\beta_{2}\right)$ bad projects will still be around. Table 1 specifies how the number of good and bad projects evolves over funding rounds. As can be seen, the number of good and bad projects in funding-round $t$ are given by $\rho \Pi_{j=1}^{t-1}\left(1-\sigma_{j}\right)$ and $(1-\rho) \Pi_{j=1}^{t}\left(1-\beta_{j}\right)$, respectively.

The odds of a project being good in round $t$ are

$$
\operatorname{Pr}(\operatorname{Good} \mid \operatorname{Round}=t)=\frac{\rho \Pi_{j=1}^{t-1}\left(1-\sigma_{j}\right)}{\rho \Pi_{j=1}^{t-1}\left(1-\sigma_{j}\right)+(1-\rho) \Pi_{j=1}^{t}\left(1-\beta_{j}\right)} .
$$

As time goes by, more and more bad projects are purged from the pool. The number of good

\footnotetext{
${ }^{6}$ The computational burden of the contracting problem at the chosen $T$ is quite high, as is discussed in footnote 9 .
} 
projects will also fall due to the successes. Thus, the odds of being good can rise or fall with the funding round, depending on which type of projects are exiting the pool the fastest, at least theoretically. Without the evaluation technology the odds of a project being good must decline by funding round, since then $\beta_{j}=0$ for all $j$. By this account, the venture capitalist should invest less in a startup as funding rounds progress, something at odds with the data as discussed by Lerner (1998). The introduction of the evaluation technology admits the possibility that "lemons ripen faster than plums."

\subsection{The Optimal Contract}

The optimal contract between the entrepreneur and the venture capitalist will specify for the length of the relationship: (i) the precision of evaluation, as given by the $\beta_{t}$ 's; (ii) the investments in development as reflected by the $\sigma_{t}$ 's; (iii) the exactness of monitoring as measured by the $\mu_{t}$ 's; and (iv) the payments that an entrepreneur who finds success in round $t$ must make to the intermediary, or the $p_{t}$ 's. The optimal contract is summarized by the outcome of the following maximization problem:

$$
C(x ; \mathbf{x})=\max _{\left\{\beta_{t}, \sigma_{t}, \mu_{t}, p_{t}\right\}}(1-\tau) \sum_{t=1}^{T} \rho \Pi_{j=1}^{t-1}\left(1-\sigma_{j}\right) \delta^{t} \sigma_{t}\left[I\left(x ; \mathbf{g}_{\mathbf{x}}^{t} \mathbf{x}\right)-p_{t}\right]
$$

subject to:

1. The round- $t$ incentive constraints

$$
\begin{aligned}
& \operatorname{Pr}(\text { Good } \mid \text { Round }=t) \times(1-\tau) \times\left\{\delta \sigma_{t}\left[I\left(x ; \mathbf{g}_{\mathbf{x}}^{t} \mathbf{x}\right)-p_{t}\right]\right. \\
& \left.+\left(1-\sigma_{t}\right) \sum_{i=t+1}^{T} \Pi_{j=t+1}^{i-1}\left(1-\sigma_{j}\right) \delta^{i+1-t} \sigma_{i}\left[I\left(x ; \mathbf{g}_{\mathbf{x}}^{i} \mathbf{x}\right)-p_{i}\right]\right\} \\
& \quad \geq\left(1-\mu_{t}\right) \max _{\widetilde{\sigma}_{t} \in\left[0, \sigma_{t}\right]}\left(D\left(\sigma_{t}\right)-D\left(\widetilde{\sigma}_{t}\right)\right. \\
& +\operatorname{Pr}(\operatorname{Good} \mid \operatorname{Round}=t) \times(1-\tau) \times\left\{\delta \widetilde{\sigma}_{t}\left[I\left(x ; \mathbf{g}_{\mathbf{x}}^{t} \mathbf{x}\right)-p_{t}\right]\right. \\
& \left.\left.\quad+\left(1-\widetilde{\sigma}_{t}\right) \sum_{i=t+1}^{T} \Pi_{j=t+1}^{i-1}\left(1-\sigma_{j}\right) \delta^{i+1-t} \sigma_{i}\left[I\left(x ; \mathbf{g}_{\mathbf{x}}^{i} \mathbf{x}\right)-p_{i}\right]\right\}\right)
\end{aligned}
$$

for $t=1, \cdots, T$, where $\operatorname{Pr}(\operatorname{Good} \mid \operatorname{Round}=t)$ is given by $(5)$; 
2. The round- $t$ limited liability constraints

$$
I\left(x ; \mathbf{g}_{\mathbf{x}}^{t} \mathbf{x}\right)-p_{t} \geq 0, \text { for } t=1, \cdots, T
$$

3. The round-0 zero-profit condition

$$
\begin{aligned}
& \rho \sum_{t=1}^{T} \Pi_{j=1}^{t-1}\left(1-\sigma_{j}\right) \delta^{t} \sigma_{t} p_{t}+\Pi_{j=1}^{T}\left(1-\sigma_{j}\right) \delta^{T} \xi I\left(x ; \mathbf{g}_{x}^{T} \mathbf{x}\right) \\
& -\sum_{t=1}^{T}\left[\rho \Pi_{j=1}^{t-1}\left(1-\sigma_{j}\right)+(1-\rho) \Pi_{j=1}^{t}\left(1-\beta_{j}\right)\right] \delta^{t-1}\left[D\left(\sigma_{t}\right)+\phi_{t}+M_{t}\left(\mu_{t}\right)\right] \\
& \quad-\sum_{t=1}^{T}\left[\rho \Pi_{j=1}^{t-1}\left(1-\sigma_{j}\right)+(1-\rho) \Pi_{j=1}^{t-1}\left(1-\beta_{j}\right)\right] \delta^{t-1} E\left(\beta_{t}\right)-R\left(\frac{x}{\mathbf{x}}\right)=0 .
\end{aligned}
$$

The objective function in $(\mathrm{P} 2)$ reflects the fact that $\mathrm{VC}$ is a competitive industry. A contract must maximize the expected return for the entrepreneur, subject to the two constraints (6) and (8). The term $I\left(x ; \mathbf{g}_{\mathbf{x}}^{t} \mathbf{x}\right)-p_{t}$ gives the payoff to the entrepreneur should the enterprise be floated in round $t$. The payoff could come from executing stock options or convertible shares. It is taxed at the capital gains rate, $\tau$. The maximized value of objective function, $C(x ; \mathbf{x})$, specifies the worth of the financial contract for the entrepreneur. This expected discounted payoff is a function of the entrepreneur's idea, $x$.

Equation (6) is the incentive compatibility constraint for a round-t project. The lefthand side gives the expected return to the entrepreneur when he undertakes the level of development investment linked with $\sigma_{t}$. The term $\operatorname{Pr}(\operatorname{Good} \mid$ Round $=t)$ represents the Bayesian odds of having a good project at the beginning of round $t$, conditional on the entrepreneur still dealing with the venture capitalist. The right-hand side gives the return when the entrepreneur deviates and picks the level of development linked with $\widetilde{\sigma}_{t}$. The level of development represented by $\widetilde{\sigma}_{t}$ maximizes the value of the deviation. The return from deviating will only materialize if the entrepreneur is not caught cheating, which has the odds $1-\mu_{t}$; if caught cheating, which occurs with probability $\mu_{t}$, then the contract is terminated and the entrepreneur receives nothing.

The incentive constraint has a dynamic element to it. If the entrepreneur invests less in development today, he lowers the odds that a good project will be successful in the current period. He increases the probability that a success, if it happens, will occur in the future; 
thus, an intertemporal tradeoff is involved. It is established in the Theory Appendix that the solution to the above problem using the one-shot incentive constraint (6) is equivalent to formulating a more general problem that uses a single consolidated round-0 incentive constraint where multi-shot deviations are allowed and that takes into account how each deviation affects the probability of success in the future-Lemmas 2 and 3.

The limited liability constraint for the entrepreneur in round $t$ is given by equation (7). The venture capitalist cannot take more than the flotation value of the startup. The last equation, or (8), is the zero-profit constraint. The first two terms are the expected present value of the cash that the venture capitalist expects to receive. This includes any scrap value. The remaining terms are the venture capitalist's expected costs. Observe that there is a fixed cost, $\phi_{t}$, connected with operating a startup project in round $t$. Last, the venture capitalist must cover the initial research cost, $R(x / \mathbf{x})$. Since VC is a competitive industry, the expected present value of the cash inflow exactly offsets the expected present value of the cash outflow.

Now, it is easy to see that the ability of the venture capitalist to monitor the entrepreneur is important. Focus on the incentive constraint (6). If $\mu_{t}=1$, say because the cost of monitoring is zero, then the left-hand side of the constraint will always exceed the righthand side. This transpires no matter what the solution for $\widetilde{\sigma}_{t}$ is, as dictated by the righthand side of (6). In this situation, the first-best solution to problem (P2) can be obtained. Alternatively, suppose $\mu_{t}=0$, because the cost of monitoring is infinite. Then, the incentivecompatible contract specifies that $\sigma_{t}=\widetilde{\sigma}_{t}$. To see this, pull the $D\left(\sigma_{t}\right)$ term over onto the left-hand side of (6). Note that the terms on the left- and right-hand sides are then the same, except that they involve $\sigma_{t}$ on the left and $\widetilde{\sigma}_{t}$ on the right. But $\widetilde{\sigma}_{t}$ maximizes the right-hand side, implying that the right-hand side must then equal the left-hand side. This can only be the case if $\sigma_{t}=\widetilde{\sigma}_{t}$, which greatly limits the contract and may result in an allocation far from first-best. If the incentive constraint binds tightly (i.e., if its Lagrange multiplier is positive) then monitoring is always done. ${ }^{7}$

Taxes interact with the incentive constraint in an interesting way. If the entrepreneur can divert development funds into nontaxable consumption, then the incentive problem becomes more severe when taxes are raised, because the left-hand side of (6) decreases proportionately with $1-\tau$, while the right-hand drops less than proportionately, ceteris paribus. This implies that a larger share of any IPO will have to be given to the entrepreneur to insure incentive

\footnotetext{
${ }^{7}$ Suppose not. Then the venture capitalist could increase monitoring slightly. This would increase the value of the Lagrangian, since the multiplier is positive. But, it would have no impact on the zero-profit condition because the marginal cost of monitoring is zero. Hence, doing no monitoring cannot be optimal when the incentive constraint binds.
} 
compatibility. This discourages the VC from financing the ventures. In fact without (6) taxes would not affect the choice variables in problem (P2) because legal expenses can be deducted from profits before any taxation; i.e., then taxes would just amount to a monotonic transformation of the objective function. Taxes would still affect the economy but only because they have an impact on the flow of new entrepreneurs.

\subsection{The Choice of Idea}

The entrepreneur is free to pick the type of venture, $x$, that he pitches to the venture capitalist. He selects the one that maximizes his expected discounted profits. Therefore, $x$ solves

$$
V(\mathbf{x})=\max _{x} C(x ; \mathbf{x})
$$

where the value of the entrepreneur's contract, or $C(x ; \mathbf{x})$, is specified by problem (P2). The shape of the $C(x ; \mathbf{x})$ function determines the value of $x$ picked by the entrepreneur. So if better intermediation increases the marginal return from $x$, then $\mathrm{VC}$ will increase growth. Note that the cost of researching $x$, or $R(x / \mathbf{x})$, is embedded in the zero-profit condition (8) connected with problem (P2). The function $V(\mathbf{x})$ gives an entrepreneur's expected discounted payoff from a startup.

\section{General Equilibrium}

Attention is now directed to formulating the model's general equilibrium. To embed the partial equilibrium analysis into a general equilibrium setting, the inflow of new startups is pinned down and a non-VC-funded sector is introduced. There exists a balanced-growth path in this endogenous growth framework and the key features of the balanced growth path are detailed at the end of this section.

\subsection{The Inflow of New Startups}

Recall that an entrepreneur incurs an opportunity cost in the amount wo to run a project. Therefore, only those new entrepreneurs with $w \mathfrak{o} \leq V(\mathbf{x})$ will choose to engage in a startup. Now, $\mathfrak{o}$ is distributed according to the cumulative distribution function $O(\mathfrak{o})$. Therefore, $O(V(\mathbf{x}) / w)$ entrepreneurs will approach the venture capitalist for funding. Consequently, 
the number of new entrants, $\mathfrak{e}$, is given by

$$
\mathfrak{e}=O(V(\mathbf{x}) / w)
$$

\subsection{The Non-VC-Funded Sector}

The non-VC-funded firm's profit maximization problem is

$$
\max _{k, l}\left\{z^{\zeta} k^{\kappa} l^{\lambda}-r k-w l\right\}
$$

where $z$ evolves according to (4). These firms raise capital through traditional intermediation at the gross interest rate $1 / \delta$. VC-funded firms also raise capital this way after they are floated.

\subsection{Balanced Growth}

The analysis focuses on analyzing a balanced-growth path for the model. Along a balancedgrowth path, the rental rate on capital, $r$, is some fixed number. In particular, the rental rate on capital will be

$$
r=1 / \delta-\mathfrak{d}
$$

where $\delta$ is the market discount factor and $\mathfrak{d}$ is the depreciation factor on capital. In balanced growth, the market discount factor, $\delta$, is given by

$$
\delta=\widehat{\delta} \mathbf{g}_{w}^{-\varepsilon}
$$

where $\widehat{\delta}$ is the representative agent's discount factor and $\varepsilon$ denotes his coefficient of relative risk aversion. ${ }^{8}$

${ }^{8}$ Suppose that entrepreneurs and workers both have a utility function (in period 1) of the form

$$
\sum_{t=1}^{\infty} \widehat{\delta}^{t-1} c_{t}^{1-\epsilon} /(1-\epsilon),
$$

where $c_{t}$ is period- $t$ consumption. Both inelastically supply one unit of raw labor. Workers earn wages from their labor and interest on their savings. To keep things simple, assume that entrepreneurs live together and pool all income. Those who don't run a startup each produce wo units of output at home with their labor. This home-produced output isn't counted as part of GDP. Entrepreneurs consume all of their output in a period. 
The idea distribution for VC-backed firms will now be characterized. To this end, let $\mathfrak{n}_{t}$ represent the number of VC-backed firms that are operating with an idea, $x_{-t}$, that was generated $t$ periods ago. Attention will now be turned to specifying the number $\mathfrak{n}_{t}$. Now, no firms will operate in the VC-backed sector with productivity level $x$, since this type is not operational yet. Each period, $\mathfrak{e}$ new entrepreneurs will be funded by the venture capitalist. Hence, $\mathfrak{n}_{1}=\mathfrak{e} \rho \sigma_{1}$ firms will operate with an idea generated one period ago, $x_{-1}$. Likewise, there will be $\mathfrak{n}_{2}=\mathfrak{e} \rho \sigma_{1} \mathfrak{s}+\mathfrak{e} \rho\left(1-\sigma_{1}\right) \sigma_{2}$ firms operating with a two-period-old idea, $x_{-2}$. So, the number of firms operating with an idea, $x_{-t}$, from $t \leq T$ periods ago is

$$
\mathfrak{n}_{t}=\mathfrak{e} \sum_{i=1}^{t} \rho \Pi_{j=1}^{i-1}\left(1-\sigma_{j}\right) \sigma_{i} \mathfrak{s}^{t-i}, \text { for } t=1, \cdots, T
$$

The venture capitalist only funds entrepreneurs for $T$ periods. Consequently, the number of operational firms with an idea from more than $T$ periods ago survive at the exogenous rate $\mathfrak{s}$ so that

$$
\mathfrak{n}_{T+j}=\mathfrak{s}^{j} \mathfrak{n}_{T}, \text { for } j \geq 1,
$$

which implies that the number of firms operating older than $T$ is simply $\mathfrak{n}_{T} \mathfrak{s} /(1-\mathfrak{s})$. The total number of operational VC-backed firms, $\mathfrak{n}$, is

$$
\mathfrak{n}=\sum_{t=1}^{T} \mathfrak{n}_{t}+\frac{\mathfrak{n}_{T} \mathfrak{s}}{1-\mathfrak{s}} .
$$

In a stationary equilibrium the distribution function over VC-funded firms using an age- $t$ idea will remain constant; that is, $\mathfrak{n}_{t}^{\prime}=\mathfrak{n}_{t}$. It is easy to see from (13) that this will be true provided that $\mathfrak{e}$ and the $\sigma_{i}$ 's are constant.

In balanced growth the wage rate, $w$, will grow at some constant gross rate, $\mathbf{g}_{w}$. To determine this growth rate, note that a VC-funded firm with productivity level $x$ will hire labor in the amount

$$
l(x ; w)=\left(\frac{\kappa}{r}\right)^{\kappa / \zeta}\left(\frac{\lambda}{w}\right)^{(\zeta+\lambda) / \zeta} x,
$$

where again $w$ and $r$ are the current wage and rental rates, respectively. For a non-VCfunded firm, just replace the $x$ with a $z$ in the above formula. In general equilibrium, the labor market must clear each period. Suppose that there is one unit of labor available in aggregate. To calculate the aggregate demand for labor, sum over all operating firms' demands for labor, both in the VC- and non-VC-backed sectors. Equilibrium in the labor 
market requires that

$$
\sum_{t=1}^{T} \mathfrak{n}_{t} l\left(x_{-t} ; w\right)+\sum_{t=T+1}^{\infty} \mathfrak{n}_{t} l\left(x_{-t} ; w\right)+\mathfrak{m} l(z ; w)=1
$$

where $\mathfrak{m}$ is the measure of firms in the non-VC-funded sector. Along a balanced-growth path, the productivity of the latest idea grows at rate $\mathbf{g}_{\mathbf{x}}$, which gives the relative productivity across two successive vintages of startups. Therefore, the above condition can be recast as

$$
\sum_{t=1}^{T} \mathfrak{n}_{t} l\left(x_{-1} \mathbf{g}_{\mathbf{x}}^{1-t} ; w\right)+\sum_{t=T+1}^{\infty} \mathfrak{n}_{t} l\left(x_{-1} \mathbf{g}_{\mathbf{x}}^{1-t} ; w\right)+\mathfrak{m} l(\omega \mathbf{x} ; w)=1
$$

Using equations (14) and (15), this can be expressed as

$$
\left(\frac{\kappa}{r}\right)^{\kappa / \zeta}\left(\frac{\lambda}{w}\right)^{(\zeta+\lambda) / \zeta}\left[x_{-1}\left(\sum_{t=1}^{T} \mathfrak{n}_{t} \mathbf{g}_{\mathbf{x}}^{1-t}+\frac{\mathfrak{n}_{T} \mathfrak{s} \mathbf{g}_{\mathbf{x}}^{-T}}{1-\left(\mathfrak{s} / \mathbf{g}_{\mathbf{x}}\right)}\right)+\mathfrak{m} \omega \mathbf{x}\right]=1
$$

where again firms older than $T$ survive at the exogenous rate $\mathfrak{s}$.

The solution for wages, $w$, obtained from the above labor-market clearing condition, is

$$
w=\lambda\left(\frac{\kappa}{r}\right)^{\kappa /(\zeta+\lambda)} \underbrace{\left[x _ { - 1 } \left(\sum_{t=1}^{T} \mathfrak{n}_{t} \mathbf{g}_{\mathbf{x}}^{1-t}+\frac{\mathfrak{n}_{T} \mathfrak{s} \mathbf{g}_{\mathbf{x}}^{-T}}{1-\left(\mathfrak{s} / \mathbf{g}_{\mathbf{x}}\right)}\right.\right.}_{=\mathfrak{n} \mathbf{x}})+\mathfrak{m} \omega \mathbf{x}]^{\zeta /(\zeta+\lambda)}
$$

where aggregate productivity in the VC sector, $\mathbf{x}$, is

$$
\mathbf{x} \equiv \frac{x_{-1}\left[\sum_{t=1}^{T} \mathfrak{n}_{t} \mathbf{g}_{\mathbf{x}}^{1-t}+\mathfrak{n}_{T} \mathfrak{s} \mathbf{g}_{\mathbf{x}}^{-T} /\left(1-\left(\mathfrak{s} / \mathbf{g}_{\mathbf{x}}\right)\right]\right.}{\sum_{t=1}^{T} \mathfrak{n}_{t}+\mathfrak{n}_{T} \mathfrak{s} /(1-\mathfrak{s})}=\frac{x_{-1}\left[\sum_{t=1}^{T} \mathfrak{n}_{t} \mathbf{g}_{\mathbf{x}}^{1-t}+\mathfrak{n}_{T} \mathfrak{s} \mathbf{g}_{\mathbf{x}}^{-T} /\left(1-\left(\mathfrak{s} / \mathbf{g}_{\mathbf{x}}\right)\right]\right.}{\mathfrak{n}}
$$

As can be seen, wages rise with the aggregate state of the economy, $\mathbf{x}$, which grows at rate $\mathbf{g}_{\mathbf{x}}$. Therefore, wages will grow at the gross growth rate $\mathbf{g}_{\mathbf{x}}^{\zeta /(\zeta+\lambda)}$, so that

$$
\frac{w^{\prime}}{w} \equiv \mathbf{g}_{w}=\mathbf{g}_{\mathbf{x}}^{\zeta /(\zeta+\lambda)}
$$

Attention is now turned to determining the growth rate in aggregate productivity, $\mathbf{g}_{\mathbf{x}}$. All new entrepreneurs will pick the same type of project, $x$. Now

$$
\mathbf{g}_{\mathbf{x}}=\mathbf{x}^{\prime} / \mathbf{x}=x^{\prime} / x
$$


Along a balanced growth path, problem (P3) will give a solution for the entrepreneur's project type, $x$, of the form

$$
x=X \mathbf{x}, \text { with } X>1,
$$

where aggregate productivity, $\mathbf{x}$, is given (17). In other words, the productivity level chosen by new entrants will grow at the same rate as aggregate productivity, although the former will exceed the latter. Therefore,

$$
\mathbf{g}_{\mathbf{x}}=\frac{x}{x_{-1}}=\frac{X \mathbf{x}}{x_{-1}}=X\left[\sum_{t=1}^{T} \mathfrak{n}_{t} \mathbf{g}_{\mathbf{x}}^{1-t}+\frac{\mathfrak{n}_{T} \mathfrak{s}_{\mathbf{x}}^{-T}}{1-\left(\mathfrak{s} / \mathbf{g}_{\mathbf{x}}\right)}\right] / \mathfrak{n}
$$

This is a nonlinear equation in $\mathbf{g}_{\mathbf{x}}$.

It is easy to see that the aggregate capital stock and output grow at the same rate as wages. The demand for capital by a type- $x$ VC-backed firm is

$$
k(x ; w)=\left(\frac{\kappa}{r}\right)^{(1-\lambda) / \zeta}\left(\frac{\lambda}{w}\right)^{\lambda / \zeta} x .
$$

From this it is easy to deduce that $k\left(\boldsymbol{g}_{x} x ; \mathbf{g}_{w} w\right)=\mathbf{g}_{w} k(x ; w)$. The same is true for a nonVC-backed firms; just replace $x$ with $z$ to get $k\left(\boldsymbol{g}_{x} z ; \mathbf{g}_{w} w\right)=\mathbf{g}_{w} k(z ; w)$. Let the aggregate capital stock in the current period be represented by $\mathbf{k}$ and that for next period by $\mathbf{k}^{\prime}$. Then $\mathbf{k}^{\prime}=\sum_{t=1}^{\infty} \mathfrak{n}_{t} k\left(\mathbf{g}_{\mathbf{x}} x_{-t} ; \mathbf{g}_{w} w\right)+\mathfrak{m} k\left(\boldsymbol{g}_{x} z ; \mathbf{g}_{w} w\right)=\mathbf{g}_{w}\left[\sum_{t=1}^{\infty} \mathfrak{n}_{t} k\left(x_{-t} ; w\right)+\mathfrak{m} k(z ; w)\right]=\mathbf{g}_{w} \mathbf{k}$, so that the aggregate capital stock grows at gross rate $\mathbf{g}_{w}$. A similar argument can be used to show that aggregate output grows at the same rate.

Definition (Balanced-Growth Path) For a given subjective discount factor and coefficient of relative risk aversion, $\widehat{\delta}$ and $\varepsilon$, a balanced-growth path consists of (i) a financial contract, $\left\{\beta_{t}, \sigma_{t}, \mu_{t}, p_{t}\right\}$, between entrepreneurs and the venture capitalist; (ii) a set of labor inputs for $V C$ - and non-VC-funded firms, $l(x ; w)$ and $l(z ; w)$; (iii) values for the contract, an IPO, and a startup, $C(x ; \mathbf{x}), I(x ; \mathbf{x})$, and $V(\mathbf{x}) ;(i v)$ a project type, $x$, for new entrepreneurs; ( $v)$ an inflow of new entrepreneurs, $\mathfrak{e}$; (vi) a rental rate for capital, $r$, and a market discount factor, $\delta$; (vii) an idea distribution for VC-funded firms, $\left\{\mathfrak{n}_{t}\right\}_{t=1}^{\infty}$; (viii) a wage rate, w; and (ix) a gross growth rate of aggregate productivity, $\mathbf{g}_{\mathbf{x}}$, such that:

1. The financial contract, $\left\{p_{t}, \sigma_{t}, \mu_{t}, \beta_{t}\right\}$, solves problem (P2), given the function $I(x ; \mathbf{x})$ and $x, \mathbf{g}_{\mathbf{x}}$, and $\mathbf{x}$. The solution to this problem gives the expected return to a new entrepreneur from the contract, $C(x ; \mathbf{x})$.

2. The VC-funded firm maximizes its profits, given $x, r$, and $w$, as specified by problem (P1). This determines the value of its IPO, I $(x ; \mathbf{x})$, as presented in (3). The solution 
to the firm's maximization problem gives the rule for hiring labor (15). Analogously, a non-VC-funded firm maximizes its profits, given $z, r$ and $w$, as specified by problem (10).

3. A new entrepreneur picks the project type, $x$, to solve problem (P3), given the value of the contract, $C(x ; \mathbf{x})$, as a function of $x$ and $\mathbf{x}$. This determines the expected value of a startup, $V(\mathbf{x})$.

4. The inflow of new entrepreneurs, $\mathfrak{e}$, is regulated by (1) and (9), taking as given the value of the startup, $V(\mathbf{x})$.

5. The rental rate on capital, $r$, and the market discount factor, $\delta$, are governed by (11) and (12), given $\mathbf{g}_{w}$.

6. The idea distribution for VC-funded firms, $\left\{\mathfrak{n}_{t}\right\}_{t=1}^{\infty}$, is specified by (13) and (14).

7. The market-clearing wage rate, $w$, is given by (16) and grows at the gross rate $\mathbf{g}_{w}=$ $\mathbf{g}_{\mathbf{x}}^{\zeta /(\zeta+\lambda)}$.

8. Aggregate productivity in the VC sector, $\mathbf{x}$, grows at the gross rate $\mathbf{g}_{\mathbf{x}}$ specified by (18).

The lemma below establishes that the setup will have a balanced-growth path.

Lemma 1 (Balanced Growth) Let $x^{\prime}=\mathbf{g}_{\mathbf{x}} x$ and $\mathbf{x}^{\prime}=\mathbf{g}_{\mathbf{x}} \mathbf{x}$ for all time. If $\beta_{t}, \sigma_{t}, \mu_{t}, p_{t}$ and $C(x ; \mathbf{x})$ solve the contract specified by $(P \mathscr{Q})$ for $(x, \mathbf{x})$, then $\sigma_{t}^{\prime}=\sigma_{t}, \mu_{t}^{\prime}=\mu_{t}, \beta_{t}^{\prime}=\beta_{t}$, $\tilde{\sigma}_{t}^{\prime}=\widetilde{\sigma}_{t}, p_{t}^{\prime}=\mathbf{g}_{w} p_{t}$, and $C\left(x^{\prime} ; \mathbf{x}^{\prime}\right)=\mathbf{g}_{w} C(x ; \mathbf{x})$ will solve it for $\left(x^{\prime}, \mathbf{x}^{\prime}\right)$. Likewise, if it is optimal in (P3) to pick $x$ for $\mathbf{x}$, then it is optimal to choose $x^{\prime}=\mathbf{g}_{\mathbf{x}} x$ for $\mathbf{x}^{\prime}$. The gap between the frontier, $x$, and average productivity in the $V C$ sector, $\mathbf{x}$, as measured by $x / \mathbf{x}$, is time invariant. The inflow of new entrepreneurs, $\mathfrak{e}$, is a constant, so that $\mathfrak{e}^{\prime}=\mathfrak{e}$.

Proof. See Theory Appendix.

\section{Calibration}

The model is now confronted with the U.S. data. To do this, values must be assigned to the model's various parameters. This is done in two ways. First, some parameters are directly imposed based on readily available information. The remaining parameters are selected to maximize the fit of the model with respect to a set of data targets. Start with the parameters that are directly imposed. VC partnerships are of a limited duration, usually between 7 to 10 years, as discussed in Historical Appendix 12. So, the analysis assumes 
Parameter Values, Directly Imposed

\begin{tabular}{lll}
\hline \hline Parameter value & Description & Identification \\
\hline Firms & & \\
$\kappa=1 / 3 \times 0.80$ & Capital's share & Standard \\
$\lambda=2 / 3 \times 0.80$ & Labor's share & Standard \\
$1-\mathfrak{d}=0.07$ & Depreciation rate & Standard \\
$\mathfrak{s}=0.96$ & Firm survival rate & Expected life of Compustat firms \\
$\begin{array}{l}\text { Consumers } \\
\varepsilon=2\end{array}$ & CRRA & Standard \\
$\widehat{\delta}=0.994$ & Discount factor & $4 \%$ risk-free rate \\
VC & & \\
$T=7$ & Number of funding rounds & Partnership length (10.5 years) \\
$\tau=0.15$ & Capital gains tax rate & H\&S (2016) \\
\hline
\end{tabular}

Table 2: The parameter values used in the baseline simulation that can be directly assigned from readily available information.

that an entrepreneur's contract with a venture capitalist has 7 potential funding rounds each lasting 1.5 years. ${ }^{9}$ Thus, partnerships are structured to last at most 10.5 years. The decreasing returns to scale parameter in the production function (2) is taken from Guner, Ventura, and $\mathrm{Xu}$ (2008), which requires setting $\zeta=0.20$. The exponents for the inputs are picked so that capital earns $1 / 3$ of nonprofit income and labor receives $2 / 3$. The survival rate of a firm is selected so that on average a publicly listed firm lives 25 years, as in the U.S. economy. The depreciation rate on capital, $1-\mathfrak{d}$, is taken to be 7 percent. Last, Henrekson and Sanandaji (2016) report that the key personnel connected with VC startups are taxed in the United States at a 15 percent capital gains rate. So, set $\tau=0.15 .^{10}$ The long-run interest rate is set to 4 percent, a typical value. A standard value of 2 is assigned for the coefficient of relative risk aversion. The market discount factor is the reciprocal of the equilibrium interest rate, and it will change as the growth rate of the economy, $\mathbf{g}_{w}$, changes. For 1948 to 2015, U.S. GDP per hours worked grew at 1.8 percent per year. Therefore, in the calibrated equilibrium, the representative agent's annual discount factor is determined by the formula $\widehat{\delta}=(1-0.04) /(1.018)^{-2}$; cf. (12). This yields a yearly interest rate of 4 percent. Table 2 presents the parameter values that are assigned from prior information.

\footnotetext{
${ }^{9}$ The computational burden of the contracting problem (P2) is quite large. With 7 periods the problem involves 28 choice variables, 14 inequality constraints, and 1 equality. Adding additional periods is therefore costly.

10 The capital gains tax rate has varied across time in the United States. The 15 percent rate was instituted under President Bush in 2003. The maximum rate rose to 20 percent in 2012 under President Obama.
} 
Turn now to the rest of the parameters. The model has 17 remaining parameters, shown in Table 3, along with their basis for identification, that will calibrated to match 22 data targets, listed in Table 4. For the most part, the model's parameter values are jointly determined as a function of the data targets. Still, some data targets play a much more central role in identifying a parameter, as discussed now. The parameters governing the efficiency of VC financing, $\chi_{D}, \chi_{E}$, and the $\chi_{M}$ 's, are particularly important here. The identification of these parameters, in addition to research productivity, $\chi_{R}$, is detailed in Appendix 10. The parameter governing the efficiency of doing research, $\chi_{R}$, is important for determining the economy's growth rate; again, the target for the economy's long-run annual growth rate is 1.8 percent, which serves to identify $\chi_{R}$.

To calibrate the elasticity of the research cost function, $\iota$, the following firm-level regression is run using VentureXpert data:

$$
\ln (\mathrm{IPO} \text { VAlue })=\underset{(0.154)}{0.390^{* *}} \times \ln (\mathrm{VC} \text { FUnding })+\text { Controls }, \text { obs. }=1,145
$$

where the controls are the logarithm of the firm's employment, the firm's age at IPO, a 2digit SIC industry dummy variable, the logarithm of the aggregate level of VC funding, and a cluster dummy for whether the venture capitalist was located in California or Massachusetts. Three instrumental variables are also used: the capital gains tax rate (which varies across states and time), dependence on external finance (which varies across industries), and the deregulation dummy. The coefficient shows the impact of a firm's VC funding on its IPO value and is used to identify a value for $\iota$, as discussed next.

To identify $\iota$, the impact of a change in firm-level VC funding on its IPO value is calculated for the model. This calculation is broken down into two steps. First, the elasticity of $I(x ; \mathbf{x})$ with respect to $x$ is computed. Second, the elasticity of $\mathrm{VC}$ funding with respect to $x$ is totaled up numerically. This is done in partial equilibrium to match the results of the firm-level regression. The ratio of these two elasticities gives the elasticity of IPO value with respect to VC funding. Thus, the following object is computed for the model:

$$
\text { IPO Value Elasticity }=\frac{d \ln \mathrm{IPO} / d \ln x}{d \ln (\mathrm{VCFundinG}) / d \ln x} .
$$

Ideally, this should have a value of 0.390 . 
Another key elasticity in the model is the shape parameter, $\nu$, for the Pareto distribution governing the opportunity cost of entrepreneurship. This regulates the inflow of entrepreneurs. Henrekson and Sanandaji (2016) report that a 1 percent increase in a country's effective tax rate on VC activity leads to a 1 percent decline in the VC-investment-to-GDP ratio. This elasticity is targeted to recover the shape parameter, $\nu$. The shape parameter can be selected after calibrating the remaining parameters because the scale parameter, $v$, can be adjusted, given the choice for $\nu$, such that the number of entrepreneurs is constant. This normalization for $v$ implies that all the other moments used in the calibration will not change. Targeting this elasticity serves to discipline the model's prediction concerning the connection between VC taxation and growth, as will be discussed in Section 7 .

The process for the efficiency of round- $t$ monitoring, $\chi_{M, t}$, is taken to be a cubic:

$$
\chi_{M, t}=\ln \left(a_{0}+a_{1} \times t+a_{2} \times t^{2}+a_{3} \times t^{3}\right) .
$$

This requires specifying four parameters, namely $a_{0}, a_{1}, a_{2}$ and $a_{3}$. Additionally, the monitoring parameters are selected to match the venture capitalist's share of equity by funding round (this pattern is taken up below)-see the Identification Appendix. The more efficient monitoring is, the higher the venture capitalist's share of equity will be, as a thought experiment conducted in Section 9 illustrates. Upon calibration this parameterization implies that monitoring costs decline in a concave manner across funding rounds at an average annual rate of 33 percent.

The time profile for the fixed cost, $\phi(t)$, is governed by the quartic

$$
\phi(t)=\exp \left(b_{0}+b_{1} \times t+b_{2} \times t^{2}+b_{3} \times t^{3}+b_{4} \times t^{4}\right) .
$$

Five parameters, $b_{0}, b_{1}, b_{2}, b_{3}$, and $b_{4}$, govern this specification. The pattern of $\mathrm{VC}$ investment by funding round (discussed below) determines these parameters. ${ }^{11}$ This formulation leads to fixed costs rising in a concave fashion at 20 percent annually.

Bernstein, Giroud, and Townsend (2016) estimate the impact on investment of a venture capitalist's time cost for monitoring. To do this, they examine the effect of changes in airline routes that reduce the commuting time a venture capitalist spends visiting a startup. They find that the introduction of a new airline route (the treatment) leads to a 4.6 to 5.2 percent increase in VC investment. The average reduction in travel time is significant. The lead investor visits the company site roughly 20 times per year and spends approximately 12

\footnotetext{
${ }^{11}$ When determining the order of the polynomials for the monitoring and fixed costs functions, the most parsimonious representation for each function that fits the data is chosen.
} 
hours traveling and 5 hours at the company per visit, which amounts to 100 contact hours annually. ${ }^{12}$ On average, a treatment saves roughly 2 hours per trip, or 40 hours per year of a venture capitalist's time. Accordingly, the treatments correspond to fairly large reductions in monitoring costs: A reduction of 2 hours per trip translates into a 12.4 percent reduction in monitoring costs. Bernstein, Giroud, and Townsend (2016) argue that the resource spent the most by a venture capitalist on monitoring is time. So, assume that monitoring is done using labor in the model. ${ }^{13}$

In the model, the size of this micro-level elasticity depends, among other things, on the quality of the projects, captured by $\rho$. As the share of good projects rises, the success rate for ventures increases while the failure rate falls. The payoff from investing in research and development hence rises, as does the return from monitoring, because more funds are being invested. Hence, the size of the treatment effect in the model moves up with $\rho$. Therefore, matching Bernstein, Giroud, and Townsend's (2016) treatment effect, in partial equilibrium, helps to tie down the fraction of good ideas, $\rho$.

Next, projects that are funded by venture capitalists have an average success rate per funding round of 2.0 percent and a failure rate of 3.2 percent. The calibration procedure attempts to match these two statistics. To construct these statistics for the model, note that the success rate in funding-round $t$ is just the number of IPOs divided by the mass of surviving firms:

$$
\operatorname{Success}_{R_{A T E}}=\frac{\operatorname{IPOs}_{t}}{\operatorname{SuRVIVING~FIRMS~}_{t}}=\frac{\sigma_{t} \rho \Pi_{j=1}^{t-1}\left(1-\sigma_{j}\right)}{\rho \Pi_{j=1}^{t-1}\left(1-\sigma_{j}\right)+(1-\rho) \Pi_{j=1}^{t}\left(1-\beta_{j}\right)} .
$$

The analogous definition for the failure rate in round $t$ is

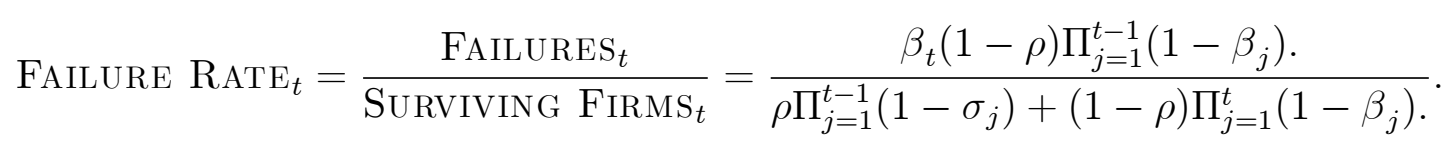

Not surprisingly, the development efficiency parameter, $\chi_{D}$, is instrumental in determining the average success rate, while the evaluation efficiency parameter, $\chi_{E}$, impinges heavily on

\footnotetext{
12 The time spent visiting the company is quoted in the unpublished version of Bernstein, Giroud, and Townsend (2016).

13 Again, it doesn't matter whether one thinks about monitoring costs as being expressed in terms of goods or labor. Let $\mathbf{m}$ represent aggregate spending on monitoring and $\mathbf{o}$ denote aggregate output. Along a balanced growth path, $\mathbf{m} / \mathbf{o}$ is constant since $\mathbf{m}$ and $\mathbf{o}$ both grow at the same rate as wages. Now, $\mathbf{m} / \mathbf{o}$ is the fraction of aggregate labor that is indirectly used to produce monitoring services. These costs show up in the labor-market clearing condition in a roundabout way through the demand for labor by firms producing output. They can be taken out directly instead, though. This is just a matter of accounting convention.
} 
Parameter Values, Calibrated

\begin{tabular}{lll}
\hline \hline Parameter value & Description & Identification \\
\hline Firms & Research efficiency, $x$ & Growth rate \\
$\chi_{R}=4.7$ & Research cost elasticity, $x$ & Regression (19) \\
$\iota=2.56$ & Pareto shape parameter & H\&S (2016) tax elasticity \\
$\nu=0.025$ & Pareto scale parameter & Normalization \\
$v=0.57$ & & \\
$\mathrm{VC}$ & Fraction of good ideas & BG\&T (2016) treatment effect \\
$\rho=0.21$ & Development efficiency, $\sigma$ & Average success rate \\
$\chi_{D}=0.0335$ & Evaluation efficiency, $\beta$ & Average failure rate \\
$\chi_{E}=0.0360$ & Monitoring efficiency, $\mu$ & Equity share by round \\
$a=\{-1.12,-0.12,0.321,-0.018\}$ & VC funding by round \\
$b=\{-0.89,0.80,0.25$, & Fixed costs, $\phi$ & \\
$\xi=0.079$ & & Cash multiple \\
Non-VC-funded & Scrap value fraction & \\
$m=40$ & & Relative empl. non-VC firms \\
$\omega=1 / 58$ & Number non-VC firms & Relative size of non-VC firms \\
\hline
\end{tabular}

Table 3: The parameter values used in the baseline simulation that are fit using the data targets listed in Table 4.

the average failure rate. The identification of these parameters is discussed in Appendix 10. Some thought experiments concerning them are presented in Section 9.

Puri and Zarutskie (2012, Table I) report that the ratio of employment in a VC-backed firm to a non-VC-backed firm is 58.14. This is a calibration target. For the model, the employment ratio is

$$
\text { Employment Ratio }=\frac{\left(\frac{\kappa}{r}\right)^{\kappa / \zeta}\left(\frac{\lambda}{w}\right)^{(\zeta+\lambda) / \zeta} \mathfrak{n x} / \mathfrak{n}}{\left(\frac{\kappa}{r}\right)^{\kappa / \zeta}\left(\frac{\lambda}{w}\right)^{(\zeta+\lambda) / \zeta} \mathfrak{m} \omega \mathbf{x} / \mathfrak{m}}=\frac{1}{\omega}
$$

This ratio pins down the productivity of a non-VC-backed firm relative to a VC-backed firm, or $\omega$.

Data on the scrap value of unsuccessful ventures are, unfortunately, not readily available. So, the parameter $\xi$ governing the scrap value of a firm is identified by attempting to match the observed cash multiple for VC investments. The cash multiple is the ratio of the venture capitalist's cash receipts to disbursements and is used as a crude measure of the ex post return on a VC investment. A venture capitalist's receipts will include the scrap value on those unsuccessful projects that are still surviving at the end of the contract. 


\section{Calibration Targets}

\begin{tabular}{lll}
\hline \hline Target & Data & Model \\
\hline Economic growth & $1.80 \%$ & $1.78 \%$ \\
Cash Multiple & 5.5 & 5.6 \\
Success Rate & $2.0 \%$ & $2.0 \%$ \\
Failure Rate & $3.2 \%$ & $3.3 \%$ \\
VC funding & Figure 7 & \\
Equity Share & Figure 7 & \\
IPO Value Elasticity-firm level & 0.39 & 0.39 \\
Tax Elasticity of VC Inv/GDP & -1.0 & -1.0 \\
Monitoring-Cost Treatment & 4.6 to 5.2\% & $4.9 \%$ \\
VC Employment Share & $5.5 \%$ & $4.8 \%$ \\
Employment ratio & 58.1 & 58.1 \\
\hline
\end{tabular}

Table 4: All data sources are discussed in the Empirical Appendix.

\subsection{Model Fit, Targeted Observations}

The upshot of the calibration procedure is now discussed. First, the model matches the average success and failure rates very well, as shown in Table 4. And, the model replicates perfectly the ratio of VC-backed employment to non-VC backed employment. The IPO elasticity is duplicated. The model matches exactly the Henrekson and Sanandaji (2016) tax rate elasticity. The monitoring-cost treatment effect lies within the range of estimates reported by Bernstein, Giroud, and Townsend (2016).

Next, note how investment in a project by a venture capitalist increases with the funding round (see the left panel of Figure 7). This time profile is a calibration target. Given the limited lifespan of a $\mathrm{VC}$ partnership, there is considerable pressure to bring a project to fruition as quickly as possible. This is true in the model too, which displays the same increasing profile of funding. Two features help to generate this. The first is that bad projects get purged over time through the evaluation process. The second is that the cost of monitoring drops as the venture capitalist becomes more familiar with the project, which reduces the incentive problem. Without these features, funding would fall over time. Last, since investment increases over time, one would expect that the venture capitalist's share of the enterprise will too. The right panel of Figure 7 illustrates this. The model does very well on this account. Again, the calibration procedure focuses on this feature of the data. 


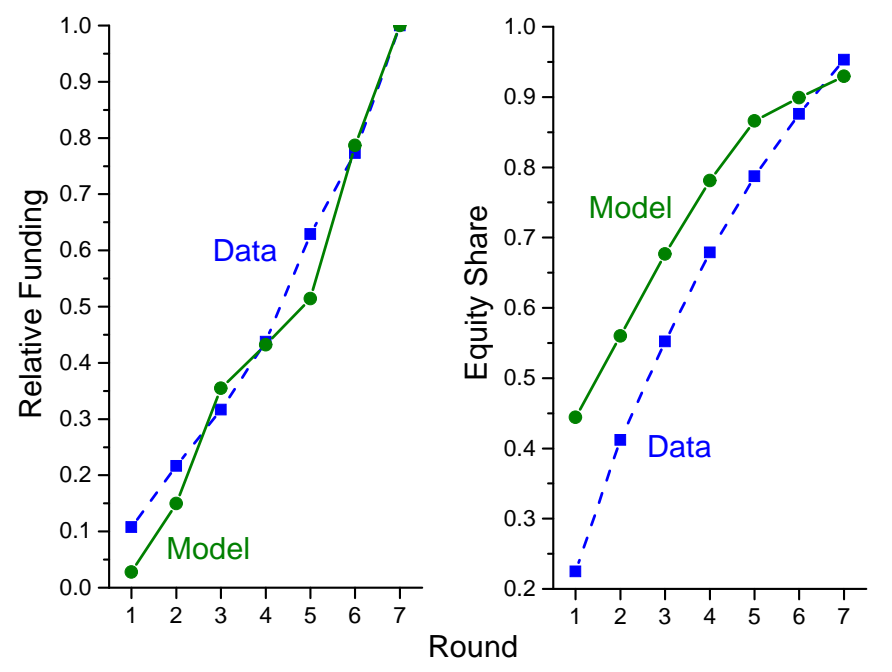

Figure 7: Investment and equity share by funding round-data and model. The left panel shows the venture capitalist's investment by funding round. Funding in the last round is normalized to 1.0. The right panel charts the venture capitalist's share of equity by funding round.

\subsection{Model Fit, Non-Targeted Observations}

The time profiles for the success and failure rates are not targeted in the calibration procedure. As shown in the middle panel of Figure 8, in the data, the odds of success decline by funding round or with the passage of time. While the model captures the average success across funding rounds very well, it has some difficulty mimicking the declining time profile. Failure rates also decline with time, and the model does very well on this dimension. Now turn to the bottom panel of Figure 8. Observe that the value of an IPO drops with the incubation time for the project. In the model, as time passes, the value of a project declines because aggregate productivity in the VC sector catches up with the productivity of the entrepreneur's venture; "the thrill is gone," so to speak. It is a bit surprising that the framework can match almost perfectly this feature of the data, which is not targeted.

\section{Technological Progress in the Financial Sector}

Over time there has been considerable technological progress in the financial sector, just as there has been in the non-financial sector. VC is emblematic of technological advancement in the financing of cutting-edge startups. The impact of financial development on economic 

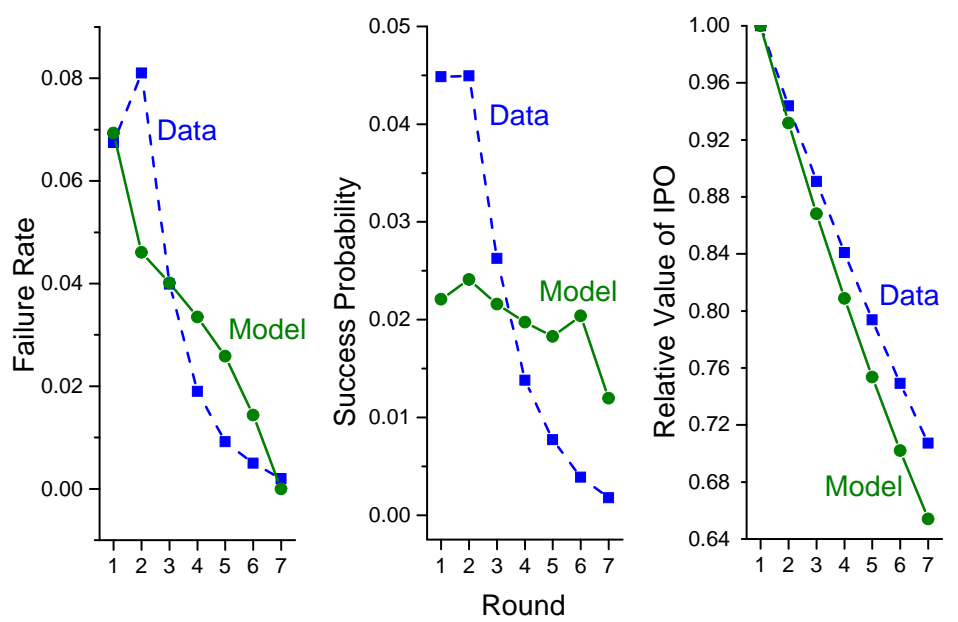

Figure 8: The odds of success and failure by funding round and the value of an IPO by the duration of funding-data and model. The value of an IPO that occurs during the first funding round is normalized to 1.0. None of these profiles are targeted in the calibration.

growth and welfare is examined here. Economists have long been interested in the effect of finance on economic growth. Cameron (1963) notes that Scotland in 1750 was a very poor country engaged in subsistence agriculture. Less than 100 years later Scotland was an industrial powerhouse. He states that the Scottish industrial revolution was even more spectacular than the English one. Conducive to this rapid industrial development was rapid financial development. Scottish banks took deposits from the general public and made loans to businesses. They also raised cash for their lending activity by issuing currency. Entrepreneurs could often borrow with no tangible securities. Banks monitored borrowers via a system of branch offices that restrained the abuse of borrowing privileges. Using data from 10,528 parishes in England and Wales during the Industrial Revolution, Heblich and Trew (2019) find "a robust and large causal effect of local financial services on the local growth of industrial employment." This supports Cameron's (1963) view.

Levine (2005) exhaustively surveys the empirical evidence on the connection between financial development and economic development. He argues that financial development leads to higher rates of growth in income and productivity. A structural model of financial and economic development is confronted with the cross-country data in Greenwood, Sanchez, and Wang (2013). They find that technological innovation in the financial sector leads to lower borrowing/savings interest-rate spreads and higher incomes. Cole, Greenwood, and Sanchez (2016) develop a model where differences in the efficiency of the financial sector 
explain the differences in technology adoption by India, Mexico, and the United States. Ji, Teng, and Townsend (2021) present a structural model in which banks choose where to open new branches. They use the model to study the rapid growth in the number of regions with commercial bank branches in Thailand between 1986 and 1996, following a financial liberalization in the 1980s. A new branch leads to more accessible credit in its local market and lowers costs to mobilize deposits. They show that Thailand's GDP growth derives mostly from those regions that were distant from bank branches in 1986 and that received new branches in the following years. So, given past work on the causal link between finance and development it seems reasonable to believe that VC should affect growth; the evidence presented in the Empirical Appendix-Section 11-suggests that this is indeed so.

VC has significantly improved the efficiency of financing inventive startups. In particular, venture capitalists lend development and evaluation expertise to startups that alternative forms of finance, such as angel investors, banking, and more recently, crowdfunding, do not. Arguably, venture capitalists are also better at monitoring projects. Venture capitalists are highly skilled: 58 percent of them have an MBA degree, 33 percent studied engineering or science in college, 7 percent have a Ph.D. in science, and 8 percent hold a JD degree. In addition, they graduated from prestigious universities: 37 percent attended an Ivy League university, 19 percent went to Harvard, and 14 percent went to Stanford. ${ }^{14}$ Additionally, the structure of VC contracts aligns the incentives of both entrepreneurs and venture capitalists to bring a startup to fruition in a timely manner. All of this amounts to a change in the organizational form of financing startups that renders it much more efficient.

To examine the impact of financial development on the economy, the efficiency of development, evaluation, and monitoring are all varied in an equiproportional manner from the calibrated equilibrium. The data points for the calibrated equilibrium are illustrated by the vertical line denoted benchmark. The upshot of this exercise is shown in Figure 9. As the efficiency of the financial sector increases, so does the economy's growth rate (as can be seen in the upper panel). This occurs because both research and development in the economy are boosted. This leads to an improvement in welfare, measured in terms of consumption. The share of employment (the middle panel) accounted for by VC-backed firms rises with financial sector efficiency, as does the likelihood of a successful startup (as measured by the average value of $\sigma$ ). The average failure rate (not shown) declines since more of the bad startups can be purged from the economy. Last, the share of startups owned by venture capitalists moves in unison with financial sector productivity (bottom panel). When

\footnotetext{
14 Source: Zarutskie, Rebecca. 2010. "The Role of Top Management Team Human Capital in Venture Capital Markets: Evidence from First Time Funds," Journal of Business Venturing, 25 (1): 155-172.
} 


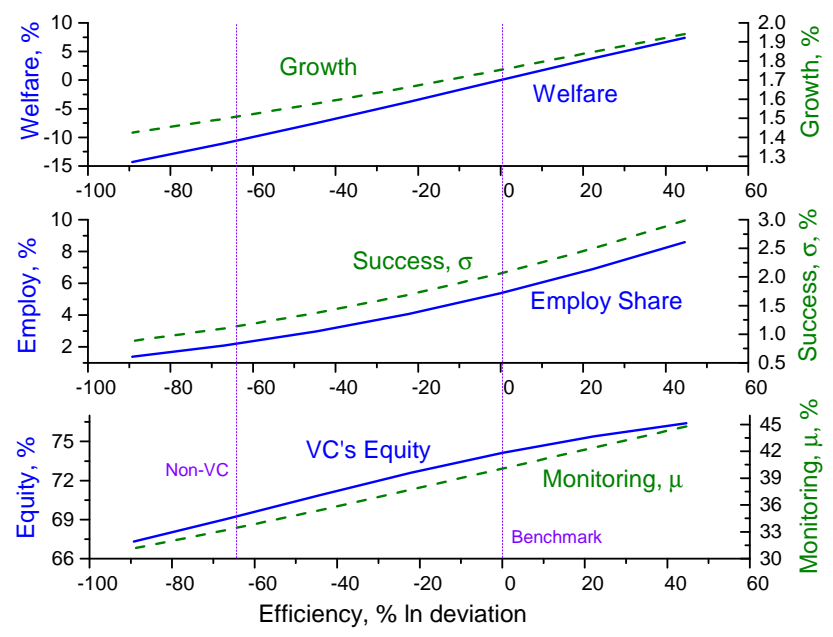

Figure 9: The impact that technological progress in the financial sector has on the macro economy. The horizontal axis measures the percentage change in efficiency (in natural log differences) from the calibrated equilibrium.

monitoring is better, malfeasance can be detected more easily (as measured by the average value of $\mu$ ). Therefore, less of the profits from a successful startup need to be shared with entrepreneurs in order to persuade them not to divert resources for personal gain. Puri and Zarutskie (2012) report that the success rate for non-VC-backed firms is 30 percent of that for VC-backed firms. To obtain this in the model, development, evaluation, and monitoring efficiency would all have to be reduced by 64 percent of their benchmark value. ${ }^{15}$ The data points corresponding to this level of efficiency are marked by non-VC line. Last, to highlight the three key roles that VC plays in the current analysis, some thought experiments that independently vary the ability to evaluate, develop, and monitor startup projects are presented in Appendix 9.

\footnotetext{
15 This efficiency calculation for non-VC firms is done in partial equilibrium to duplicate its empirical counterpart from the Puri and Zarutskie (2012) study.
} 


\section{The Impact of VC Taxation on Growth and Welfare}

\subsection{Tax Codes and VC Activity: Cross-Country Evidence and Implications for Growth}

How does the tax code affect the incentives of entrepreneurs and venture capitalists? The model can be used as a laboratory to gauge the effect of taxation on key variables, such as growth and welfare. Recall from Section 5 that the model is calibrated to match the elasticity of taxes on the VC-investment-to-GDP ratio, as estimated from cross-country data; the cross-country data are discussed below. The targeting of this elasticity disciplines the analysis.

Most VC-funded firms in the United States are set up as partnerships. CEOs, central employees, founders, and investors are paid in terms of convertible equity and stock options. These financial assets pay off only under certain well-specified contingencies and serve to align the incentives of key participants. ${ }^{16}$ Interestingly, the returns on convertible equity and stock options are taxed in the United States at the capital gains rate, which is 15 percent. The IRS lets companies assign artificially low values to these instruments when they are issued. So, effectively, participants are only subject to taxation at the time of an acquisition/IPO.

In other countries the rate of taxation on VC-funded startups is much higher. Figure 10 illustrates how VC investment as a percentage of GDP falls with the tax rate on VC profits for a cross section of countries. The data are from Henrekson and Sanandaji (2016). To obtain the tax rates on VC profits, they asked the local offices of PricewaterhouseCoopers in 22 countries to calculate the effective tax rate for a representative VC startup. This way of computing the tax effective rates is well suited for the current analysis because it takes into account tax avoidance (i.e., the use of legitimate methods in the tax code for minimizing taxes paid). So, for example, PricewaterhouseCoopers calculate that the effective tax rate is 30 percent in France, 47.5 percent in Germany, and 72 percent in Italy. Using this data in a regression analysis, Henrekson and Sanandaji (2016, Table 4) report a strong negative correlation between the tax rates on VC profits and VC investment as a percentage of GDP. The elasticity of the tax rate on $\mathrm{VC}$ activity is about -1.0 , as mentioned earlier. This feature of the data is matched in the model by calibrating the shape parameter for the Pareto distribution, which governs the inflow of entrepreneurs. So, the response of VC

\footnotetext{
${ }^{16}$ Celik and Tian (2018) analyze how established firms with better corporate governance (as proxied by the equity share of institutional investors) also tend to remunerate executives more in terms of incentive pay than do other firms, which leads to higher levels of innovation.
} 


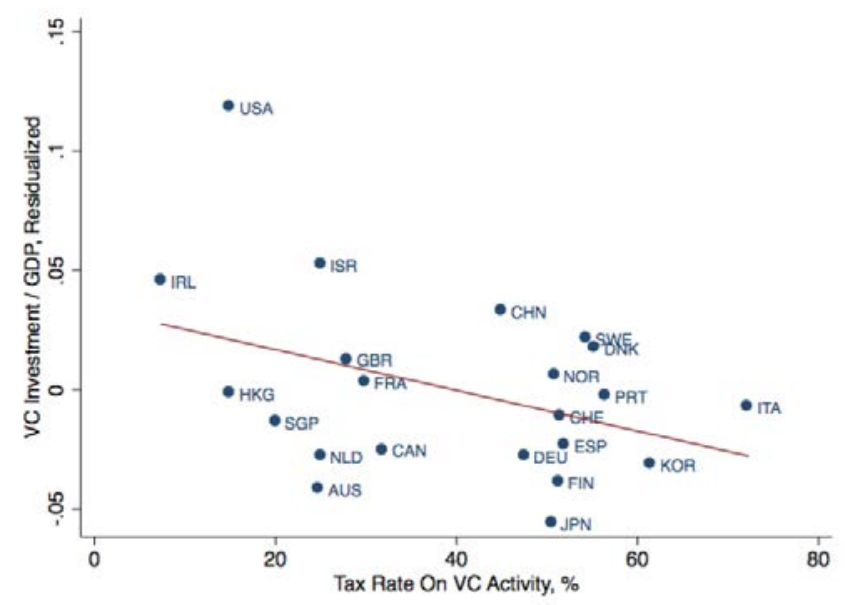

Figure 10: The conditional cross-country relationship between the tax rate on VC profits and the VC-investment-to-GDP ratio. The numbers are expressed as percentages. The conditioning variables are similar to those used in Henrekson and Sanandaji (2016). See the Empirical Appendix for a list of the controls.

activity to taxes is the same in the data and model. Recall that higher taxes increase the incentive of entrepreneurs to divert investment funds into nontaxable consumption. Without the incentive compatibility constraint, taxes do not have a significant impact on economic growth. Thus, it would be hard to match the implied negative relationship between economic growth and taxation, via the VC-investment-to-GDP ratio, displayed in Figure 5.

The effect of taxation on growth and welfare in the model is shown in Figure 11. As the tax rate on $\mathrm{VC}$ profits rises, not surprisingly economic growth declines. An increase in the tax rate from -15 percent (a subsidy) to 50 percent, causes economic growth in the model to fall from 1.90 percent to 1.58 percent. The effects on growth might appear small, but lowering the tax rate from 50 percent to 15 percent produces a long-run welfare gain of 9.4 percent, when ignoring transitional dynamics. Going further from 15 percent to -15 percent generates an additional welfare gain of 5.5 percent, all measured in terms of consumption.

\subsection{What Hinders French Growth: VC Efficiency and/or High Taxation?}

To illustrate how the model can be used to understand the role that venture capital plays in creating divergences in growth across countries, a comparison of France versus the United States is undertaken. The central question here is how do differences in taxation and VC 


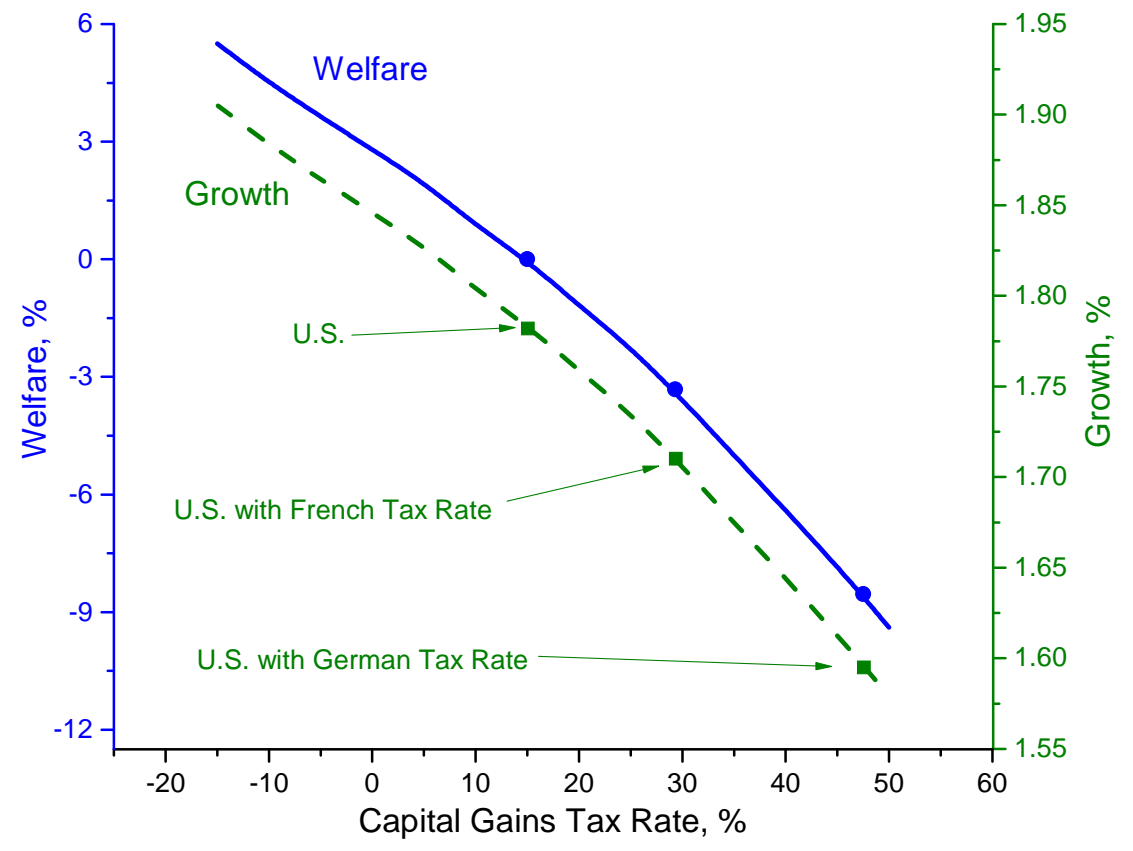

Figure 11: Impact of VC profit taxation on economic growth and welfare.

efficiency in the two countries affect the difference in their growth rates. To do this, four key parameters, namely $\chi_{D}, \chi_{E}, \chi_{M}$, and $\tau$, are calibrated so that the model resembles the French economy. Since these parameters do not encompass all of the differences between France and the United States, the baseline model for France will not explain the entire discrepancy between the French (1.3 percent) and U.S. (1.8 percent) growth rates.

First, the tax rate on VC activity, or $\tau$, for France is set at 30 percent, the number reported by Henrekson and Sanandaji (2016). Second, Greenwood, Sanchez, and Wang (2013) estimate that the French financial sector is 23 percent less efficient than in the United States. Their estimate best applies to the efficiency of evaluation and monitoring undertaken by financial intermediaries, or $\chi_{E}$ and $\chi_{M}$ : The functional form they use for the cost of monitoring is a close cousin of the functional forms used here for evaluation and monitoring costs. Third, the last parameter is $\chi_{D}$, which represents the efficiency of VC firms in developing projects. (Again, some thought experiments analyzing separately the importance of $\chi_{D}, \chi_{E}$, and $\chi_{M}$ are presented in Appendix 9.) As mentioned in Section 6, VC firms in the United States employ highly skilled individuals. For France, $\chi_{D}$ is calibrated so that its VC-investment-to-GDP ratio is 25 percent of the U.S. one.

Taking stock of things, three factors will then contribute to the divide in French-U.S. growth due to differences in their financial systems: (i) financial intermediaries' capabilities 
to acquire information about projects' worthiness and to tackle agency problems (as captured by $\chi_{E}$ and $\chi_{M}$ ); (ii) the ability of intermediaries to lend expertise to develop projects (as reflected by $\chi_{D}$ ); and (iii) differences in tax rates that affect the profitabilities of intermediaries investing in startups $(\tau)$. The results of the exercise are presented in Table 5 . To begin with, the rate of growth in the baseline French economy is 1.44 percent, which is about 70 percent of the actual gap between French and U.S. growth. Factors excluded from the analysis account for the remaining 30 percent. It turns out that the difference in expertise for developing projects is more important than difference in tax rates which in turn is more important than the difference in the ability to screen and monitor projects.

There would be only a tiny gain from French intermediaries improving their capabilities to screen projects and monitor the use of funds. This would close 6 percent of the difference between French and U.S. growth. This does not say that evaluating and monitoring projects is not important. The results in Appendix 9 show that they have significant impact on growth and welfare. Rather, it says that they are not major factors in accounting for the difference between French and U.S. growth. ${ }^{17}$ Lowering French taxes on startups to the U.S. level would make up 18 percent of the gap. While this is a significant effect, tax reform would be a daunting task for France to undertake. Last, increasing the ability of French intermediaries to develop startups has the biggest impact, filling 44 percent of the divide. These are services that traditional financial intermediaries barely provide. Venture capitalists sit on the boards of directors of their portfolio companies and are deeply engaged in the management. They provide strategic and operational guidance; they connect the entrepreneurs with investors and customers; and they are pivotal in the hiring decisions for the board members and key employees. According to Gompers et al. (2020), venture capitalists spend an average of 18 hours per week assisting their portfolio companies out of a total reported work week of 55 hours. ${ }^{18}$ Last, (ii) and (iii) are likely to be related. Financiers are more likely to acquire the skills and talent to develop startups when the latter is profitable, a factor omitted from the analysis.

Does this accord with reality? Continental Europe has been plagued by the "European Paradox," strong basic science but a poor commercialization of it. To spur entrepreneurship, the government weighs heavily in the European VC industry. It is the largest limited partner,

\footnotetext{
${ }^{17}$ Indeed, Cole, Greenwood, and Sanchez (2016) illustrate that monitoring could play a significant role in explaining why poorer countries don't adopt advanced technologies.

18 Again, one can easily think about the development costs as being expressed in terms of labor-see footnote 13 .
} 
France-U.S. COMPARISON

\begin{tabular}{llllllll}
\hline \hline Variable & Mon. & Eval. & Dev. & Taxes & VC Inv & Growth \% & Gap filled \\
& $\frac{\chi_{M}}{\chi_{M}^{U S}}$ & $\frac{\chi_{E}}{\chi_{E}^{U S}}$ & $\frac{\chi_{D}}{\chi_{D}^{U S}}$ & $\tau$ & $\frac{\frac{\mathrm{VC} \text { Inv }}{G \mathrm{DP}}}{\left(\frac{\mathrm{VI} \mathrm{In}}{G \mathrm{DP}}\right)^{U S}}$ & $100 \times g_{w}$ & $\frac{\Delta g_{w}}{g_{w}^{U S}-g_{w}^{F R}}$ \\
\hline US Baseline & 1.00 & 1.00 & 1.00 & 0.15 & 1.00 & 1.78 & $0 *$ \\
FR Baseline & 0.77 & 0.77 & 0.49 & 0.30 & 0.25 & 1.44 & $0.70^{* *}$ \\
$\Delta \chi_{M}^{F R} \& \chi_{E}^{F R}$ & 1.00 & 1.00 & 0.49 & 0.30 & 0.35 & 1.47 & 0.06 \\
$\Delta \chi_{D}^{F R}$ & 0.77 & 0.77 & 1.00 & 0.30 & 0.59 & 1.66 & 0.44 \\
$\Delta \tau^{F R}$ & 0.77 & 0.77 & 0.49 & 0.15 & 0.51 & 1.53 & 0.18 \\
\hline
\end{tabular}

Table 5: The impact of changes in evaluation, development, and monitoring efficiencies, as well as taxes, on the French growth rate. The entry with the asterisk signifies that there is no gap for the United States, while the one with the double asterisk represents the ratio of the U.S.-France growth gap under the baseline calibration to the actual gap in the data.

accounting for 29 percent of total VC fund raising. By contrast, in the United States pension funds are the largest limited partners, raising 42 percent of funds. In France, Bpifrance ${ }^{19}$ invests directly in state-owned VC funds and indirectly in private VC funds. The return on government-run VC funds have been lackluster. ${ }^{20}$ In addition, private European VC funds are demonstrated to have a positive effect on fostering firm growth, whereas governmentmanaged $\mathrm{VC}$ funds do not. Hiring fund managers or investing in private funds requires experts. As uncovered by the US-France comparison, a seasoned entrepreneur is a better fit than an experienced banker. The latter may be skilled at evaluating and monitoring projects but is poor at developing them; i.e., providing mentoring services. By comparison, Israel has been successful at starting a VC industry. To attract foreign VC investors, the Israeli government offered tax incentives and matching funds. The foreign venture capitalists brought expertise to Israel that was then emulated by their Israeli partners.

\section{Conclusion}

Venture capital is important for economic growth. Funding by venture capitalists is positively associated with patenting activity. VC-backed firms have higher IPO values when they are floated. Following flotation they have higher R\&D-to-sales ratios. VC-backed firms also grow faster in terms of employment and sales.

\footnotetext{
19 Bpifrance was established by the French government to support entrepreneurial finance.

20 According to the "Pan-European Private Equity Performance Benchmarks Study" conducted by Thomson Reuters and the European Venture Capital Association, the average 10-year internal rate of return (by the end of 2013) was 5.03 percent for the U.S. VC funds and 0.84 percent for the European VC funds.
} 
An endogenous growth model where technological innovation is financed by VC is constructed and matched with the data. In the framework, entrepreneurs bring ideas to venture capitalists for funding. A dynamic contract governs the relationship between entrepreneurs and venture capitalists. Venture capitalists provide seed money to research the ideas. After this, projects enter a funding-round cycle. During each round: (i) projects are evaluated to assess their ongoing viability; (ii) those that pass are then provided with $\mathrm{VC}$ to develop the project; (iii) the use of funds is monitored to ensure that there is no malfeasance; and (iv) successful projects are floated in the stock market or sold to other businesses. The evaluation plan, development funding, the monitoring strategy, and the equity share of the venture capitalist are governed by the dynamic contract. The contracts between entrepreneurs and venture capitalists are optimal, given the economic environment in which they operate. The model is capable of matching several stylized facts of the VC process by funding round. In particular, it mimics the funding-round profiles for the success and failure rates of projects, the injections of $\mathrm{VC}$ for development, the venture capitalist's share of equity, and the value of an IPO when it goes to market. This is done while matching the share of VC-backed firms in total employment, the average size of a VC-backed firm relative to a non-VC-backed firm, the elasticity of IPO value with respect to VC funding, the cross-country elasticity of $\mathrm{VC}$ investment with respect to profit taxes, and the impact of monitoring costs on $\mathrm{VC}$ investment.

VC represents a form of technological advancement in the financial sector. Venture capitalists are highly skilled individuals well suited to evaluating, developing, and monitoring startups that are on the frontier of innovation. VC contracts align the incentives of entrepreneurs and financiers to work together in order to ensure a successful, timely startup. The productivity gains offered by VC raise growth and promote welfare. The key personnel involved with starting up enterprises funded by venture capitalists are rewarded in the form of convertible equity and stock options. Therefore, in the United States, venture capitalists are subject only to capital gains taxation. The rate at which VC-funded startups are taxed in the United States is low relative to other developed countries. Does this promote innovative activity? The analysis suggests that raising the tax on VC-funded startups from the U.S. rate of 15 percent to the Norwegian rate of roughly 50 percent would shave 0.2 percentage points off growth and lead to a welfare loss of 9.4 percent. The cross-country evidence suggests that economic growth is positively related to investment by venture capitalists. Compared with countries in continental Europe, such as France, a more advanced VC sector is a blessing for economic growth in the United States. In particular, 44 percent of the difference between French and U.S. growth is attributed to the better value-added 
services provided by American venture capitalists to develop startups.

\section{References}

Akcigit, Ufuk, Dinlersoz, Emin, Greenwood, Jeremy, and Veronika Penciakova (2019), "Synergizing Ventures." Unpublished paper, University of Chicago.

Bergemann, Dirk and Ulrich Hege. 1998. "Venture capital financing, moral hazard, and learning," Journal of Banking and Finance, 22 (6): 703-735.

Bernstein, Shai, Giroud, Xavier, and Richard R. Townsend. 2016. "The Impact of Venture Capital Monitoring," Journal of Finance, 71 (4): 1591-1622.

Buera, Francisco J., Kaboski, Joseph P., and Yongseok Shin. 2015. "Entrepreneurship and Financial Frictions: A Macrodevelopment Perspective," Annual Review of Economics, 7 (1): 409-436.

Cameron, Rondo. 1963. "Banking in the Early Stages of Development: A Preliminary Survey," Scandinavian Economic History Review, 11 (2): 117-134.

Cavalcanti, Tiago, Kaboski, Joseph P., Martins, Bruno, and Cezar Santos. 2021. "Dispersion in Financing Costs and Development," Unpublished paper, University of Cambridge.

Celik, Murat Alp and Xu Tian. 2018. "Corporate Governance, Managerial Compensation, and Disruptive Innovations," Unpublished paper, University of Toronto.

Clementi, Gian Luca and Hugo Hopenhayn. 2006. "A Theory of Financing Constraints and Firm Dynamics," Quarterly Journal of Economics, 121 (1): 229-265.

Cole, Harold L., Greenwood, Jeremy and Juan M. Sanchez. 2016. "Why Doesn't Technology Flow from Rich to Poor Countries?" Econometrica, 84 (4): 1477-1521.

Cooley, Thomas, Marimon, Ramon, and Vincenzo Quadrini. 2004. "Aggregate Consequences of Limited Contract Enforceability." Journal of Political Economy, 112 (4): $817-847$.

Gompers, Paul, Gronell, Will, Kaplan, Steven N., and Ilya A. Strebulaev. 2020. "How Do Venture Capitalists Make Decisions?" Journal of Financial Economics, 135 (1): 169-190.

Greenwood, Jeremy, Sanchez, Juan M., and Cheng Wang, 2010. "Financing Development: The Role of Information Costs," American Economic Review, 100 (4): 18751891. 
Greenwood, Jeremy, Sanchez, Juan M., and Cheng Wang, 2013. "Quantifying the Impact of Financial Development on Economic Development," Review of Economic Dynamics, 16 (1): 194-215.

Guner, Nezih, Ventura, Gustavo, and Daniel Yi Xu. 2008. "Macroeconomic Implications of Size-Dependent Policies," Review of Economic Dynamics, 11 (4): 721-744.

Heblich, Stephan and Alex Trew. 2019. "Banking and Industrialization," Journal of the European Economic Association, 17 (6): 1753-1796.

Henrekson, Magnus and Tino Sanandaji. 2016. "Stock Option Taxation and Venture Capital Activity: A Cross-Country Study," IFN Working Paper No. 1104, Research Institute of Industrial Economics.

Hurst, Erik and Benjamin Wild Pugsley. 2011. "What Do Small Businesses Do?" Brookings Papers on Economic Activity, Fall: 73-118.

Ji, Yan, Teng, Songyuan, and Robert M. Townsend. 2019. "Branch Expansion versus Digital Banking: The Dynamics of Growth and Inequality in a Spatial Equilibrium Model," Working Paper Number 28582, National Bureau of Economic Research.

Lerner, Josh. 1998. "Comment on Bergemann and Hege," Journal of Banking $\mathscr{E}$ Finance 22 (6-8): 736-740.

Levine, Ross, 2005. "Finance and Growth: Theory and Evidence," In Philippe Aghion and Steven Durlauf, eds., Handbook of Economic Growth, ed. 1, vol. 1. Amsterdam: Elsevier, 865-934.

Opp, Christian. 2019. "Venture Capital and the Macroeconomy," Review of Financial Studies, forthcoming.

Paulson, Anna L., Townsend, Robert M., and Alexander Karaivanov. "Distinguishing Limited Liability from Moral Hazard in a Model of Entrepreneurship," Journal of Political Economy, 114 (1): 100-144.

Puri, Manju and Rebecca Zarutskie. 2012. "On the Life Cycle Dynamics of VentureCapital and Non-Venture-Capital-Financed Firms," Journal of Finance, LXVII (6): 2247-2293.

Romer, Paul M. 1986. "Increasing Returns and Long-Run Growth," Journal of Political Economy, 94 (5): 1002-1037.

Smith, Anthony Jr. and Cheng Wang. 2006. "Dynamic Credit Relationships in General Equilibrium," Journal of Monetary Economics, 53 (4): 847-877.

Spear, Stephen E. and Cheng Wang. 2005. "When to fire a CEO: Optimal termination in dynamic contracts," Journal of Economic Theory, 120 (2): 239-256. 
Townsend, Robert M. 1979. "Optimal Contracts and Competitive Markets with Costly State Verification," Journal of Economic Theory, 21 (2): 256-293.

Williamson, Stephen D. 1986. "Costly Monitoring, Financial Intermediation, and Equilibrium Credit Rationing," Journal of Monetary Economics, 18 (2): 159-79. 


\section{Thought Experiments Appendix}

The analysis stresses the ability of a venture capitalist to evaluate, develop, and monitor startup projects. The importance of these three factors is investigated one by one here. These experiments present some useful background material relevant for Section 6, Section 7.2, and Appendix 10.

\subsection{Changes in Monitoring Efficiency, $\chi_{M, t}$}

How important is the venture capitalist's ability to monitor the use of funds by entrepreneurs? Figure 12 shows the general equilibrium impact of improving the efficiency of monitoring in the model. To undertake this thought experiment, the monitoring efficiency profile, $\left\{\chi_{M, 1}, \cdots, \chi_{M, 7}\right\}$, is changed by a scalar, which takes the value of 1 for the baseline calibration. Monitoring efficiency is measured in terms of the percentage deviation of this scalar from its baseline value. As monitoring efficiency improves, there is an increase in the average odds of detecting fraud across funding rounds (see the top panel). The venture capitalist's share of equity rises, on average, because it is now easier to ensure that funds are not diverted. Compliance with the contract can still be guaranteed when the entrepreneur is given a lower share of an IPO. The venture capitalist must still earn zero profits, however. Part of the increased return to the venture capitalist is soaked up by letting the new entrepreneur be more ambitious about his choice of technique, which raises the initial cost of research, $R(x / \mathbf{x})$; the rest of the increased return is absorbed by increased investment in development. As a result, VC-backed firms have a higher level of productivity and are more successful. This results in a higher share of employment for VC-backed firms (as shown in the middle panel). Additionally, the economy's growth rate moves up, which results in a welfare gain (measured in terms of consumption; see the bottom panel). ${ }^{21}$

\subsection{Changes in Evaluation Efficiency, $\chi_{E}$}

The importance of efficiency in evaluation is examined now. The results are displayed in Figure 13, where $\chi_{E}$ is measured in terms of percentage deviations from the baseline equilibrium. As evaluation becomes more efficient, the odds of detecting a bad project increase. Hence, the average failure rate across funding rounds moves up (see the top panel).

\footnotetext{
21 See Akcigit, Celik, and Greenwood (2016, Section 5.1) for details on how the welfare gain is computed. In the current work, the initial level of consumption across balanced-growth paths is held fixed, though, as opposed to aggregate productivity.
} 

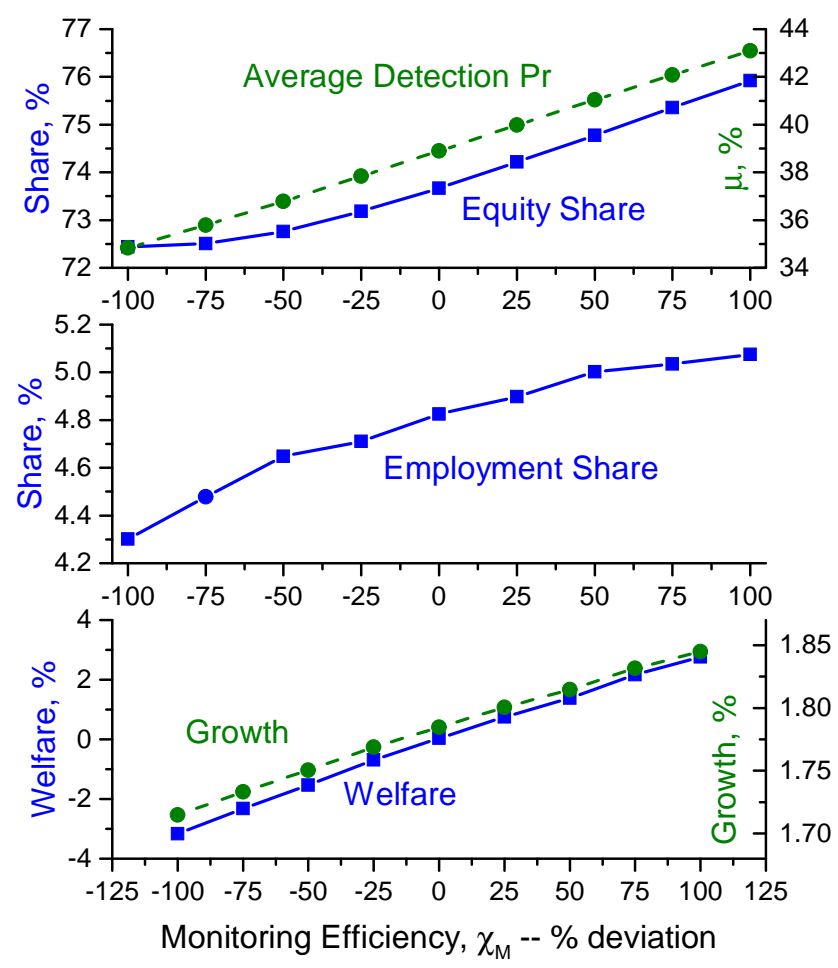

Figure 12: Efficiency in monitoring, $\chi_{M, t}$. The top panel shows how the average probability of detecting fraud across funding rounds and the venture capitalist's share of equity vary with efficiency in monitoring. The middle panel illustrates how the share of VC-backed firms in employment responds. Growth and welfare are displayed in the bottom panel. Monitoring efficiency is measured in terms of the percentage deviation (in natural log differences) from the baseline equilibrium. 

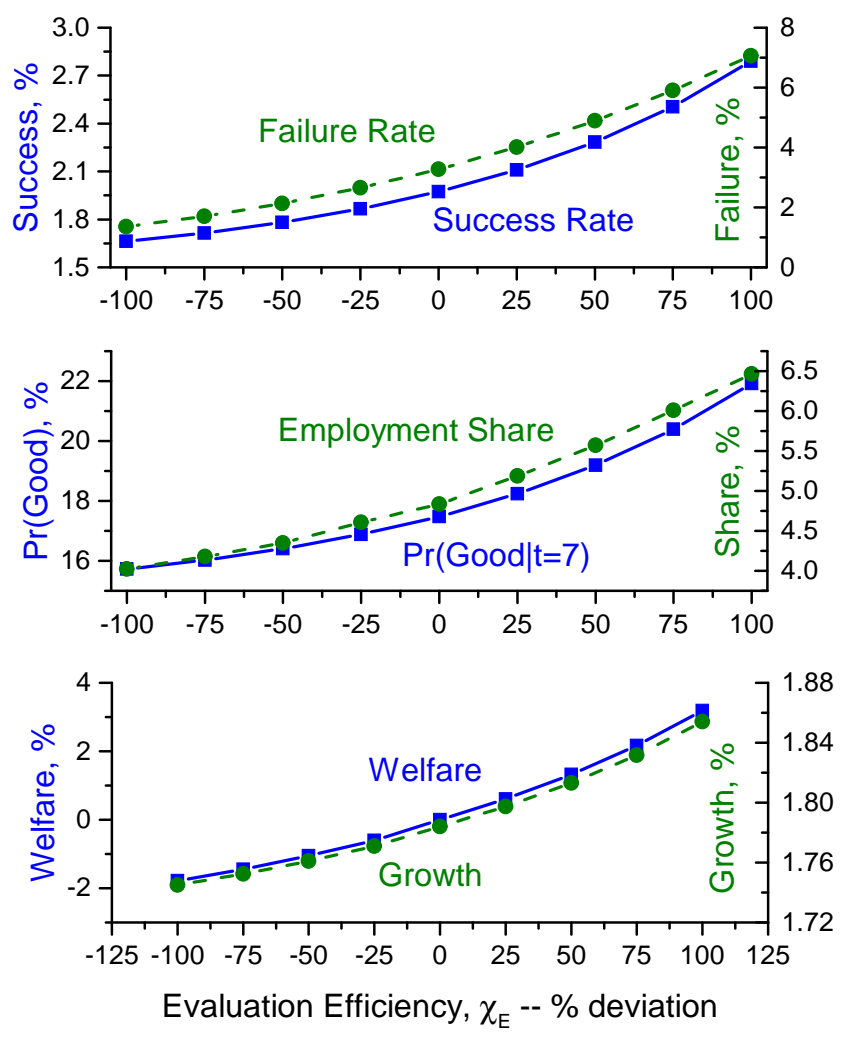

Figure 13: Efficiency in evaluation, $\chi_{E}$. The top panel shows how the average failure and success rates across funding rounds vary with efficiency in evaluation. The middle panel illustrates how the odds of a project being good in the seventh round and the employment share of VC-backed firms respond. Growth and welfare are illustrated in the bottom panel. Evaluation efficiency is measured in terms of the percentage deviation (in natural $\log$ differences) from the baseline equilibrium.

The success rate rises, both due to the purging of bad projects and the resulting increased $\mathrm{VC}$ investment in development. The purging of bad projects dominates the exit of good ones so that the fraction of good projects in the last round increases with $\chi_{E}$ (as the middle panel illustrates). The fact that it is more profitable to invest in research and development is reflected by an upward movement in the share of VC-backed firms in employment. Economic growth and welfare move up in tandem as evaluation efficiency improves (see the bottom panel). 

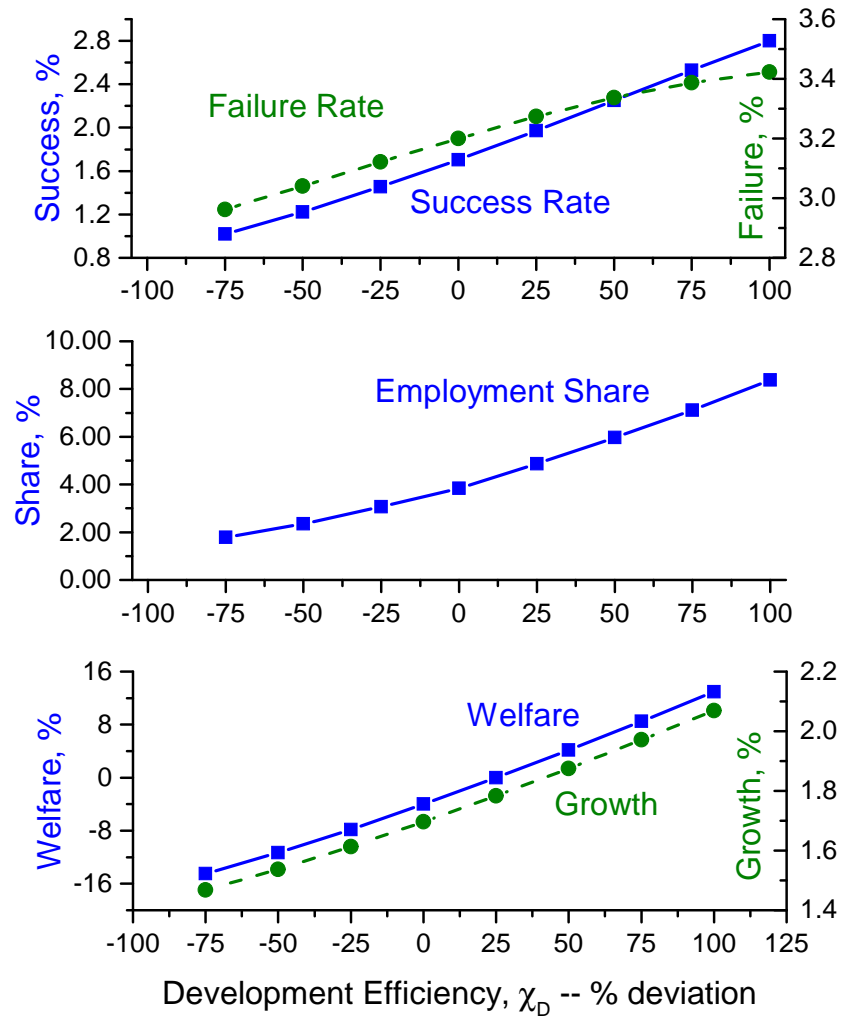

Figure 14: Efficiency in development, $\chi_{D}$. The top panel shows how the average failure and success rates across funding rounds vary with efficiency in development. The middle panel illustrates how the share of VC-backed firms in employment responds. Growth and welfare are illustrated in the bottom panel. Development efficiency is measured in terms of the percentage deviation (in natural log differences) from the baseline equilibrium.

\subsection{Changes in Development Efficiency, $\chi_{D}$}

The impact of changes in development efficiency is studied next. Again, $\chi_{D}$ is measured in terms of percentage deviations from the baseline calibration. As it becomes less expensive to develop a project, the odds of success improve. The failure rate also rises because fewer good projects remain in the pool over time. VC-backed firms' share of employment picks up, as it is more profitable to fund a project. Last, economic growth and welfare rise with development efficiency. 


\section{References}

Akcigit, Ufuk, Celik, Murat Alp, and Jeremy Greenwood. 2016. "Buy, Keep or Sell: Economic Growth and the Market for Ideas." Econometrica, 84 (3): 943-984.

\section{Identification Appendix}

What is VC's secret of success? How can the success of VC in the United States be emulated in the rest of the world? Addressing these questions entails decomposing VC's contributions into the evaluation, development, and monitoring channels and assessing their relative importance. Modeling VC financing by dynamic contract theory is well suited to achieve this goal of decomposition. Doing this requires assigning values to the parameters governing evaluation, development, and monitoring.

How are the VC efficiency parameters identified? A heuristic discussion of the identification strategy is presented here. As mentioned, at a general level, a shift in a parameter value influences all of the data targets. Still, at a practical level, some of the key VC parameters, in particular $\chi_{R}, \chi_{D}, \chi_{E}$, and the $\chi_{M}$ 's, affect the VC data targets, namely economic growth, the success rate, the failure rate, and the VC's share of equity, in a recursive (block diagonal) manner. Table 6 gives a tabular portrayal of the mapping from the parameters into the data targets. The import of this mapping for identification is turned to now.

1. Research Productivity, $\chi_{R}$. As can be seen from Figure 15, top panel, a shift in research productivity primarily has an impact on economic growth. Its effect on the failure and success rates and the VC's share of equity is small. This suggests that after the other parameters have been chosen to fit the data targets, $\chi_{R}$ can then be picked to match the economy's growth rate.

2. Development Efficiency, $\chi_{D}$. A shift in this parameter impacts mainly the success rate, as is shown in Figure 15, second panel. It also affects the growth rate, but in a more muted way. But, from Point 1 , the research productivity parameter, $\chi_{R}$, can be adjusted to compensate for this. The parameter $\chi_{D}$ has negligible effect on the failure rate and the VC's share of equity-these two lines lie of top of each other.

3. Evaluation Efficiency, $\chi_{E}$. Changes in evaluation efficiency have the largest effect on the failure rate-see Figure 15, third panel. The next biggest impact is on the success rate, but this can be controlled for by changing $\chi_{D}$, as discussed in Point 2 . The moderate effect on growth can be compensated for by shifting $\chi_{R}$-Point 1 . The influence of $\chi_{E}$ on the VC's share of equity is minimal. (The lines for growth and equity share lie on top of each other.) 


\section{The Mapping Between Parameters and Data Targets}

\begin{tabular}{lllll}
\hline \hline Variable & Growth & Success Rate & Failure Rate & VC's Share of Equity \\
$\chi_{R}$ & + & $\simeq 0$ & $\simeq 0$ & $\simeq 0$ \\
$\chi_{D}$ & + & + & $\simeq 0$ & $\simeq 0$ \\
$\chi_{E}$ & + & + & + & $\simeq 0$ \\
$\chi_{M}$ 's & + & + & + & + \\
\hline
\end{tabular}

Table 6: The block diagonal nature of the mapping from parameter values into data targets.

4. Monitoring Efficiency, the $\chi_{M}$ 's. To implement this experiment the monitoring efficiency profile, $\left\{\chi_{M, 1}, \cdots, \chi_{M, 7}\right\}$, is shifted by a scalar. Now, the VC's share of equity changes-Figure 15, bottom panel. While the other targets move as well, this can be adjusted for by following the steps outlined in Points 1 to 3 .

\section{Empirical Appendix}

\subsection{Evidence on Venture Capital and Firm Performance}

Some regression evidence is presented here on the link between VC, firm growth, and innovation.

\subsubsection{Venture Capital and Firm Growth}

Regression analysis is now conducted to evaluate the performance of VC-backed and non-VCbacked firms along four dimensions for the years following an IPO: the R\&D-to-sales ratio, the growth rate of employment, the growth of sales revenue, and the (natural logarithm of the) market value of firms. The results are presented in Table 7. The regressions are based on an unbalanced panel of U.S. public companies between 1970 and 2014. To compare VC-backed companies with their non-VC-backed counterparts, a VC dummy is entered as an independent variable that takes the value of 1 if the company is funded by $\mathrm{VC}$ before its IPO. In all regressions, industry dummies, year dummies, and a year dummy for the IPO are included. In addition, a cross term is added between the $\mathrm{VC}$ dummy and the number of years since the firm's IPO.

As shown by the first row of regression coefficients, VC-backed companies are more $\mathrm{R} \& \mathrm{D}$ intensive and grow faster than their non-VC-backed counterparts. On average the R\&D-tosales ratio of a public VC-backed company is higher than its non-VC-backed counterpart by 


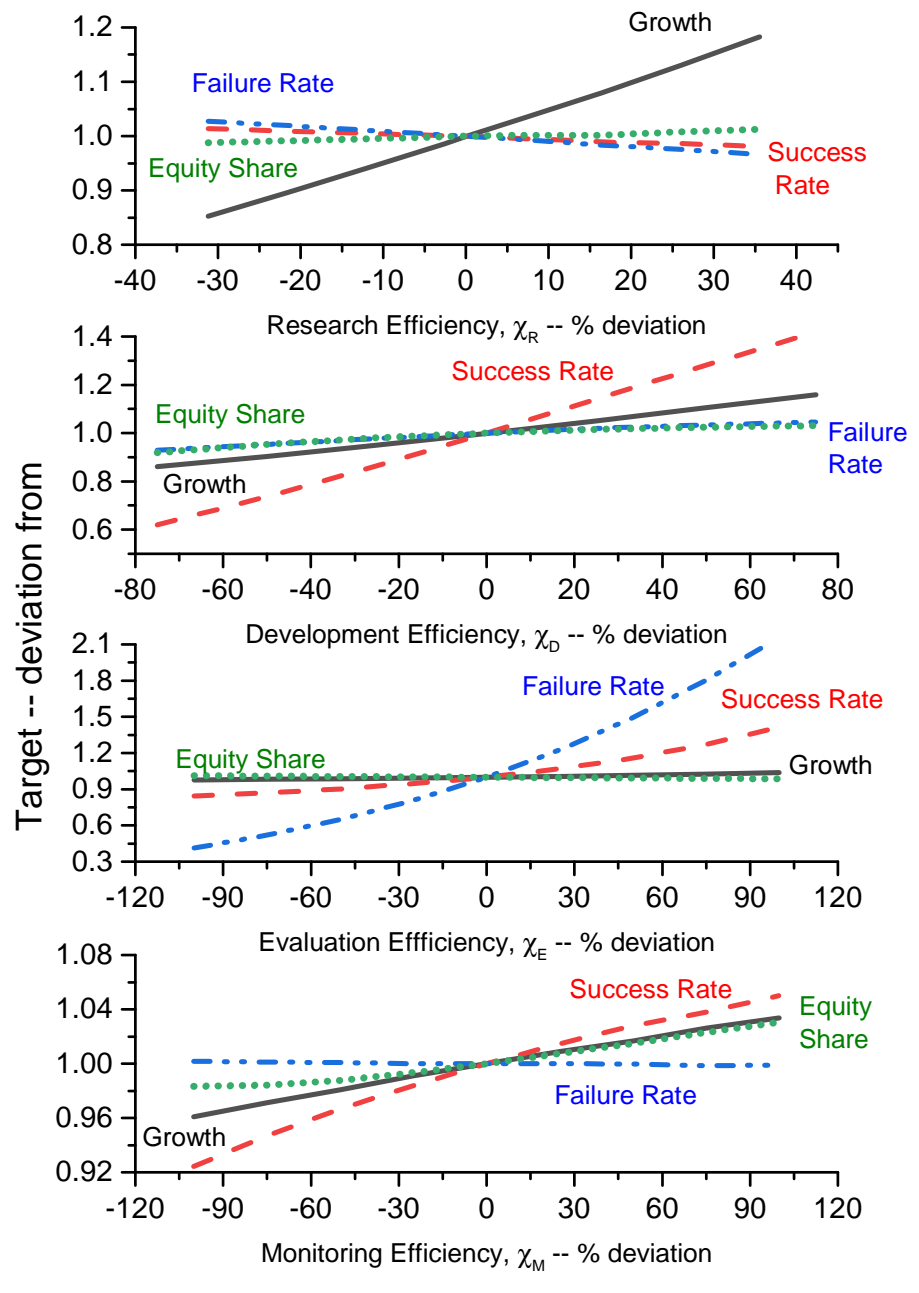

Figure 15: Identification of the research, development, evaluation, and monitoring parameters, $\chi_{R}, \chi_{D}, \chi_{E}$, and the $\chi_{M}$ 's. The horizontal axis shows the percentage deviation (in natural $\log$ differences) from the calibrated equilibrium. The vertical axis displays how the target changes relative to the benchmark equilibrium. 
VC- versus Non-VC-Backed Public Companies

\begin{tabular}{lcccc}
\hline \hline Dependent variable & RESD / Sales & Employment growth & Sales growth & $\ln$ (Firm value) \\
\hline \multirow{2}{*}{ VC $(=1$, if backed by VC) } & $0.0521^{* * *}$ & $0.0490^{* * *}$ & $0.0696^{* * *}$ & $0.373^{* * *}$ \\
& $(0.00169)$ & $(0.00206)$ & $(0.00270)$ & $(0.0141)$ \\
VC $\times$ years since IPO & $-0.000780^{* * *}$ & $-0.00304^{* * *}$ & $-0.00406^{* * *}$ & $-0.0110^{* * *}$ \\
& $(0.000132)$ & $(0.000165)$ & $(0.000215)$ & $(0.00110)$ \\
$\ln$ (employment) & $-0.0133^{* * *}$ & $-0.00567^{* * *}$ & $-0.00641^{* * *}$ & $0.851^{* * *}$ \\
& $(0.000248)$ & $(0.000254)$ & $(0.000335)$ & $(0.00170)$ \\
+ controls & & & & \\
Observations & 84,116 & 148,834 & 149,672 & 168,549 \\
R-squared & 0.383 & 0.084 & 0.108 & 0.737 \\
\hline
\end{tabular}

Table 7: All specifications include year dummies, industry dummies (at the 4-digit SIC), and a year dummy for the IPO. Standard errors are in parentheses and significance at the 1 percent level is denoted by ***.

5.2 percentage points, and it grows faster-by 4.9 percentage points in terms of employment and 7.0 percentage points in terms of sales revenue. These superior performances translate into higher market values: VC-backed companies are valued 37.3 percent higher than their non-VC-backed counterparts. The difference in performance, however, gradually dwindles over the years, as shown by the negative signs of the regression coefficients in the second row. As a consequence, the performances of VC- and non-VC-backed public companies tend to converge in the long run, though the speed of convergence is fairly low, as revealed by the magnitude of the regression coefficients in the second row.

\subsubsection{Venture Capital and Innovation}

The role of $\mathrm{VC}$ in encouraging technological innovation is now gauged at an annual periodicity; specifically, the impact of VC funding on patent performance is evaluated at the firm level and at the industry level for employment and sales growth. The data contains all companies funded by venture capitalists between 1970 and 2015. These VC-funded patentees are identified by matching firm names in VentureXpert and PatentsView.

Firm-Level Regressions. In the firm-level regressions, the primary independent variable is (the natural logarithm of) annual VC funding, while the dependent variable is a measure of patenting performance 3 years after the firm receives the funding. The primary independent variable may suffer from both measurement error and selection issues. So, an instrumental variable (IV) is used in some of the regressions. The IV is based on the dereg- 
ulation of pension funds in 1979, as highlighted in Section 12. The deregulation of pension funds reduced the fundraising costs of VC and led to increasing VC investment in all industries. In addition, industries that relied more on external finance enjoyed a stronger boost in VC funding. ${ }^{22}$ Hence, a cross term between a "deregulation dummy" and a variable reflecting the industry's (in which the firm operates) dependence on external finance is introduced as an IV. The deregulation dummy takes the value of 1 after 1979. The dependence on external finance is a Rajan-Zingales type measure that reflects the extent to which outside funds are used in the industry for expenditures on property, plant and equipment, R\&D, advertising, and employee training. In all of the regressions, controls are added for the number of patents held by the firm at the beginning of the year, the age of the firm, and the total amount of private- and federally-funded R\&D of the industry in which the firm operates. Additionally, both a year dummy and an industry dummy (at 2-digit SIC) are entered. Last, since both innovation and VC activities are remarkably clustered in California and Massachusetts, a "cluster dummy" for a firm headquartered in California and Massachusetts is included.

The results of the regression analysis are reported in Table 8. Panel A of Table 8 conducts the analysis along the extensive margin; that is, whether the firm obtains any patents 3 years after receiving VC funding. In regressions (1) and (2), the dependent variable is a dummy that takes the value of 1 if the firm files any successful patent applications at the U.S. Patent and Trademark Office (USPTO) within the 3 years following funding. Regressions (3) and (4) focus on "breakthrough" patents, a measure pioneered by Kerr (2010). Breakthrough patents refer to those in the right tail of the citation distribution. Here the dependent variable in regressions (3) and (4) is a dummy variable that takes the value of 1 if the firm files any patents in the top 10 percent of the citation distribution in its cohort (i.e., those patents with the same technological class and same application year) within the 3 years following funding. Panel B of Table 8 turns to the intensive margin. In regressions (5) and (6) the dependent variable is (the natural logarithm of) the number of patents within the 3 years ensuing the firm's funding. The (natural logarithm of the) number of patents is weighted by citations in regressions (7) and (8).

As shown by the positive regression coefficients of $\mathrm{VC}$ funding in Panel A, a firm is more likely to file a patent and come up with a breakthrough patent the larger is the funding from a venture capitalist, although the impact of VC funding is somewhat smaller in spurring breakthrough patents than ordinary patents. According to the IV estimates in regressions (6) and (8), a 10 percent increase in $\mathrm{VC}$ funding will induce a boost, in the 3

\footnotetext{
${ }^{22}$ This is revealed by the first stage results of the IV regressions. The first stage results are not presented due to space limitations; they can be sent upon request.
} 
VC Funding and Patenting

\begin{tabular}{|c|c|c|c|c|}
\hline Panel A: Firn & 2-Level Re & ressions, & Extensive. & Analysis \\
\hline Dependent variable & $1\{$ Pate & $2 t>0\}$ & $1\{$ "Break & $h$ patent $">0\}$ \\
\hline & Probit & IV & Probit & IV \\
\hline & (1) & (2) & (3) & (4) \\
\hline $\ln$ (firm VC funding) & $0.126^{* * *}$ & $0.610^{* * *}$ & $0.125^{* * *}$ & $0.525^{* * *}$ \\
\hline & $(0.0123)$ & $(0.0932)$ & $(0.0118)$ & $(0.123)$ \\
\hline+ controls & & & & \\
\hline Observations & 7,589 & 7,589 & 7,589 & 7,589 \\
\hline Panel 1 & $n$-Level Re & ressions, & Intensive 1 & Analysis \\
\hline Dependent variable & $\ln (P$ & tent) & $\ln (P$ & quality adj) \\
\hline & OLS & IV & OLS & IV \\
\hline & (5) & (6) & (7) & (8) \\
\hline $\ln$ (firm VC funding) & $0.137^{* * *}$ & $0.792^{* * *}$ & $0.182^{* * *}$ & $0.748^{* *}$ \\
\hline & $(0.0107)$ & $(0.233)$ & $(0.0173)$ & $(0.369)$ \\
\hline+ controls & & & & \\
\hline Observations & 5,538 & 5,538 & 4,958 & 4,958 \\
\hline $\mathrm{R}$-squared & 0.244 & & 0.135 & \\
\hline
\end{tabular}

Table 8: See the main text for a description of the dependent and independent variables. Standard errors are in parentheses. ${ }^{* * *}$ denotes significance at the 1 percent level, ${ }^{* *}$ at the 5 percent level.

years subsequent to funding, of 7.9 percent in patenting and 7.5 percent in quality-adjusted patenting. In addition, across all the regressions in Table 8, the estimates are consistently higher in the IV regressions.

Impact of Venture Capital on Industry Growth. How does VC affect growth at the industry level? Attention is now turned to evaluating the impact of $\mathrm{VC}$ funding on the growth of industries between 1970 and 2011. The main explanatory variable is the (natural logarithm of the) amount of $\mathrm{VC}$ funding each industry receives in each year. The dependent variables are the average annual growth rate of employment and sales for the 3 year period after an industry receives $\mathrm{VC}$ funding. ${ }^{23}$ In all the regressions, controls are added for logged employment in each industry, year dummies, and industry dummies (at 2-digit SIC). An instrumental variable (IV) is applied to address the issues of measurement errors and selection bias in the OLS regressions. As detailed earlier, the IV is a cross term between the deregulation dummy and a variable reflecting the industry's dependence on external finance.

\footnotetext{
${ }^{23}$ The employment and sales information is based on the NBER-CES Manufacturing Industry Database available at https://www.nber.org/nberces/.
} 


\begin{tabular}{|c|c|c|c|c|}
\hline \multicolumn{5}{|c|}{ VC FUNDING AND INDUSTRY GROWTH } \\
\hline \multirow[t]{2}{*}{ Dependent variable } & \multicolumn{2}{|c|}{ Employment growth } & \multicolumn{2}{|c|}{ Sales Growth } \\
\hline & OLS & IV & OLS & IV \\
\hline & $(1)$ & $(2)$ & $(3)$ & $(4)$ \\
\hline $\ln ($ industry VC funding) & $0.00338^{* * *}$ & $0.00608^{* * *}$ & $0.00495^{* * *}$ & $0.00898^{* * *}$ \\
\hline & $(0.000748)$ & $(0.00178)$ & $(0.000958)$ & $(0.00228)$ \\
\hline $\ln ($ employment $)$ & $-0.00646^{* * *}$ & $-0.00817^{* * *}$ & $-0.00476^{* *}$ & $-0.00730^{* * *}$ \\
\hline & $(0.00161)$ & $(0.00189)$ & $(0.00207)$ & $(0.00243)$ \\
\hline \multicolumn{5}{|l|}{+ controls } \\
\hline Observations & 1,909 & 1,909 & 1,909 & 1,909 \\
\hline R-squared & 0.285 & & 0.334 & \\
\hline
\end{tabular}

Table 9: See the main text for a description of the dependent and independent variables. Standard errors are in parentheses. ${ }^{* * *}$ denotes significance at the 1 percent level.

As demonstrated in Table 9, increasing $\mathrm{VC}$ funding in an industry in a given year is associated with a higher growth rate of employment and sales in the subsequent 3 years. According to the IV regressions (2) and (4), a one-standard-deviation increase in logged industry-level $\mathrm{VC}$ funding is associated with increases of 1.3 and 1.9 percentage points in annual employment and sales growth following funding. As complementary evidence on the cyclicality of VC activities, Khan and Petratos (2016) document that VC-backed firm entry (the number of startups) and exit (the number of IPOs and M\&As) are respectively almost three and five times as volatile as business fixed investment.

\section{$11.2 \quad$ Figures}

- Figure 1: The rise of venture capital, 1970 to 2015. Investment by venture capitalists is obtained from the VentureXpert database of Thomson ONE. The fraction of public firms backed by VC companies is created by matching firm names in VentureXpert and CompuStat; the latter are available from Wharton Research Data Services. ${ }^{24}$

- Figure 2: The share of VC-backed companies in employment, REDD spending, and patents. The employment and R\&D shares of VC-backed public companies are calculated by matching firm names in VentureXpert and CompuStat, as in Figure 1. The share of patents for VC-backed public companies is computed by matching firm names in VentureXpert and the NBER Patent Data Project. ${ }^{25}$

\footnotetext{
${ }^{24}$ Source link: https://wrds-web.wharton.upenn.edu/wrds/index.cfm?

${ }^{25}$ Source link: https://sites.google.com/site/patentdataproject/Home
} 


\begin{tabular}{lc}
\hline \hline VC Investment And Growth: & Cross-Country Regressions \\
\hline Dependent Variable & Growth of GDP pc., \% \\
\hline $\ln$ (VC Investment/GDP) & $0.718^{* * *}$ \\
& $(0.223)$ \\
+ control & \\
Observations & 40 \\
R-squared & 0.602 \\
\hline
\end{tabular}

Table 10: The control variables are the initial levels of real GDP per capita, the Barro and Lee (2013) human capital index, and the ratio of domestic private credit to GDP. Standard errors are in parentheses. $* * *$ denotes significance at the 1 percent levels.

- Figure 3: Top 30 VC-Backed Companies. As in Figure 1, the list of VC-backed public companies is gathered by matching firm names in VentureXpert and CompuStat.

- Figure 5: Economic growth and VC investment. VC investment and the growth rate of real GDP per capita are based on VentureXpert of Thomson ONE and the World Development Indicators of the World Bank, respectively. The countries in the sample cover 99 percent of world VC investment and 86 percent of world GDP between 2005 and 2014. A country is included in the sample if its share of world VC investment is not less than 0.03 percent and the information for the control variables is available. ${ }^{26}$ The growth rate of real GDP per capita on the vertical axis is residualized against the following control variables: the initial levels of real GDP per capita, the Barro and Lee (2013) human capital index, and the ratio of domestic private credit to GDP. The Barro and Lee (2013) human capital index is a measure of educational attainment in a country. The data for the domestic private credit-to-GDP ratio was gathered from the Global Financial Development Database of the World Bank. The first two controls are the main factors demonstrated in the empirical literature to be important for economic growth. Pioneered by King and Levine (1993a, 1993b), the last control variable has been the most widely used measure for the financial development level of a country. The regression results are reported in Table 10.

- Figure 7: Investment and equity share by funding round. Investment in each funding round is based on the VC-funded deals in Crunchbase between 1981 and 2015. Crunchbase has better funding-round information than VentureXpert. The vertical axis is the

\footnotetext{
${ }^{26}$ An exception is Bermuda, which accounted for 0.15 percent of world VC investment. Bermuda is excluded because it is a tax haven. Companies set up offices there, while undertaking virtually no business activity, just to avoid corporate income taxation.
} 
mean of funding in a round across all deals, from round 1 (i.e., series A) to round 7 (i.e., series G). Funding is converted into millions of constant $\$ 2009$ using the GDP deflator. The mean duration of a funding round in Crunchbase is 1.4 years, which is taken to 1.5 years here. The share of equity transferred to the venture capitalist in each funding round is calculated as the ratio of $\mathrm{VC}$ funding in each round to the post-money valuation of the company after the VC investment. For each funding round the mean equity share across all deals is calculated. The vertical axis is the cumulated share of equity transferred to the venture capitalist.

- Figure 8: The odds of success and failure by funding round and the value of an IPO by the duration of funding. The underlying data source is Puri and Zarutskie (2012, Table VI.B, p. 2271). The success rate refers to firms that have an IPO or that are acquired by another firm. The acquisitions in Puri and Zarutskie (2012) are converted into successes by multiplying by 0.629 . This is based on the fact that the cash multiple for acquisitions is 37.1 percent lower than for IPOs, as reported in Achleitner et al. (2012). In addition, the success and failure rates by funding round are obtained by interpolating the original annual data using a cubic spline to get a periodicity of 1.5 years. Puri and Zarutskie (2012, Table V) classify a firm "as having failed if it disappears from the LBD in its entirety." The value of an IPO, as a function of the duration of VC funding, derives from regression (2) in Table 11 (discussed in Section 11.4).

- Figure 10: The cross-country relationship between the tax rate on VC activity and the VC-investment-to-GDP ratio. The source for the cross-country data is Henrekson and Sanandaji (2016, Table 1). The VC-investment-to-GDP ratio on the vertical axis is residualized against the following control variables: GDP per capita, the Barro and Lee (2013) human capital index, the ratio of R\&D to GDP, the ratio of market capitalization of all listed firms to GDP, and the "distance to frontier score" of the World Bank (a measure of the ease of doing business in a country).

\subsection{Tables}

- Table 4: Calibration Targets. The sources for the data targets are: Economic growthBEA; cash multiple-a large-scale survey on 681 venture capital firms reported in Gompers et al (2020, Table 7); success rate, failure rate, VC employment share and employment ratio-Puri and Zarutskie (2012, Tables I and VI.B); VC funding and equity share-Crunchbase; IPO value elasticity (firm level)-Regression (19); tax elasticity of 
VC Investment/GDP-Henrekson and Sanandaji (2016); Monitoring-cost treatmentBernstein et al. (2016, Tables IAVI \& IAVII).

- Table 7: VC-versus Non-VC-Backed Public Companies. The VC-backed public companies are singled out by matching firm names in VentureXpert and CompuStat. Since the R\&D-to-sales ratios and growth rates can be very volatile across firms, the top and bottom 5 percent of the outliers are trimmed in this regression. The results are robust to changing the trimming threshold (at the 1 percent versus 5 percent level).

- Table 8: VC Funding and Patenting, Firm-Level Regressions. The VC-funded patentees are identified by matching firm names in VentureXpert and PatentsView. ${ }^{27}$ The dependence on external finance measure is motivated by Rajan and Zingales (1998). In calculating the dependence on external finance, 30 percent of selling, general, and administrative expenses is taken as intangible investment. The industry levels of privateand federally-funded R\&D are collected from the Business R\&D and Innovation Survey by the National Science Foundation. ${ }^{28}$ A truncation adjustment for citations is made. The industry dummies in this regression are at the 2-digit SIC level.

- Table 9: VC Funding and Industry Growth, Industry-Level Regressions. The employment and sales information is based on the NBER-CES Manufacturing Industry Database. $^{29}$ The industry panel is based on the 4-digit SIC. The industry dummies in this regression are at the 2-digit SIC level.

\subsection{Duration of VC Funding and the Value of an IPO}

The relationship between the firm's value at an IPO and the number of years it received funding from the venture capitalist is examined using regression analysis. The regressions are based on public companies funded by venture capitalists between 1970 and 2015. These VCbacked companies are identified by matching firm names in CompuStat and VentureXpert. The dependent variable in the regressions is the natural logarithm of the market value of the firms at IPO (in \$2009). A three-year average is used for market value because of the notorious volatility of share prices following an IPO. IPOs are excluded when they take more than 11 years for the firms to go public after receiving the first $\mathrm{VC}$ funding. This is for two reasons: (i) the sampling period is formulated to be consistent with the model where the

27 Source link of PatentsView: http://www.patentsview.org/download/.

28 Source link of BRDIS: https://www.nsf.gov/statistics/srvyindustry/\#tabs-2.

29 Source link of NBER-CES Manufacturing Industry Database: https://www.nber.org/nberces/. 
VC Funding and Years to Go Public

\begin{tabular}{lcc}
\hline \hline Dependent variable & $\ln ($ Firm value at IPO, real $)$ \\
\hline & 1 & 2 \\
years btw first VC funding and IPO & $-0.0470^{* * *}$ & $-0.0385^{* * *}$ \\
& $(0.0161)$ & $(0.0146)$ \\
firm age at IPO & & $-0.0246^{* * *}$ \\
& & $(0.00495)$ \\
\# of employees at IPO $(\mathrm{log})$ & & $0.709^{* * *}$ \\
& $\mathrm{~N}$ & $(0.0375)$ \\
year dummy for IPO & $\mathrm{N}$ & $\mathrm{Y}$ \\
industry effect & & $\mathrm{Y}$ \\
& 1,042 & 1,006 \\
Observations & 0.008 & 0.627 \\
R-squared & & \\
\hline
\end{tabular}

Table 11: Standard errors are in parentheses. ***, **, and * denote significance at the 1, 5 and 10 percent levels.

maximum duration for each VC investment is 10.5 years, and (ii) only 4.5 percent of the observations occur after 11 years with the data being very noisy. The main explanatory variable is the number of years between the firm's first VC funding and the date of its IPO. The findings are shown in Table 11. The first coefficient in regression (2) is used in Figure 8 to plot the decline in the value of an IPO across successive funding rounds.

\section{References}

Achleitner, Ann-Kristin, Braun, Reiner, Lutz, Eva and Uwe Reiner. 2012. "Venture Capital Firm Returns from Acquisition Exits," Unpublished paper, Technische Universität München.

Barro, Robert J. and Jong-Wha Lee. 2013. "A New Data Set of Educational Attainment in the World, 1950-2010," Journal of Development Economics, 104 (C): 184-198.

Kerr, William R. 2010. "Breakthrough Inventions and Migrating Clusters of Innovation," Journal of Urban Economics, 67 (1): 46-60.

Khan, Hashmat and Pythagoras Petratos. 2016. "Entrepreneurship and the Business Cycle: Stylized Facts from U.S. Venture Capital Activity," CEP 16-09, Carleton University. 
King, Robert G. and Ross Levine. 1993a. "Finance and Growth: Schumpeter Might Be Right," Quarterly Journal of Economics, 108 (3): 717-738.

King, Robert G. and Ross Levine. 1993b. "Finance, Entrepreneurship, and Growth: Theory and Evidence," Journal of Monetary Economics, 32 (3): 513-542.

Rajan, Raghuram G. and Luigi Zingales. 1998. "Financial Dependence and Growth," American Economic Review, 88 (3): 559-586.

\section{Historical Appendix: The Rise of Venture Capital as Limited Partnerships}

Financing cutting-edge technologies has always been problematic. ${ }^{30}$ It is difficult to know whether new ideas are viable, if they will be saleable, and how best to bring them to market. Also, it is important to ensure that entrepreneurs' and investors' incentives are aligned. Traditional financial institutions, such as banks and equity/securities markets, are not well suited to engage in this sort of underwriting. Historically, the introduction of new technologies was privately financed by wealthy individuals. Investors were plugged into networks of inventive activity where they learned about new ideas, vetted them, and drew on the expertise needed to operationalize them. These financiers are similar to today's "angel investors."

The Brush Electric Company provided such a network for inventors and investors in Cleveland around the turn of the 20th century. Electricity was one of the inventions born during the Second Industrial Revolution. Individuals linked with the Brush Electric Company network spawned ideas for arc lighting, liquefying air, smelting ores electrically, and for electric cars and trolleys, among other things. The shops at Brush were a meeting place for inventors; they could develop and debug new ideas with help from others. Those investors connected with the Brush network learned about promising new ideas from the scuttlebutt at the shops. They became partners/owners in the firms that they financed. Interestingly, in the Midwest at the time, prolific inventors (those with more than 15 patents) who were principals in companies were much more likely to keep their patents or assign them to the companies where they were principals as opposed to other inventors, who typically sold them to businesses where they had no concern. This aligned the incentives of innovators and investors.

\footnotetext{
30 This section draws heavily on Lamoreaux, Levenstein, and Sokoloff (2007) for the period prior to World War II and on Kenney (2011) for the period after.
} 
World War II and the start of the Cold War ushered in new technologies, such as jets, nuclear weapons, radars, and rockets. There was a splurge of spending by the Defense Department. A handful of VC firms were formed to exploit the commercialization of scientific advances. American Research and Development (ARD), founded by General Georges Doriot and others, was one of these. ARD pulled in money from mutual funds, insurance companies, and an initial public stock offering. The founders knew that it was important for venture capitalists to provide advice to the fledging enterprises in which they were investing. In 1956 ARD invested $\$ 70,000$ in Digital Equipment Corporation (DEC) in exchange for a 70 percent equity stake. ARD's share was worth $\$ 38.5$ million when DEC went public in 1966 , which represented an annual return of 100 percent. While this investment was incredibly successful, the organizational form of ARD did not come to dominate the industry. The compensation structure of ARD made it difficult for the company to retain the VC professionals needed to evaluate startups and provide the guidance necessary for success.

An alternative organizational form came to emblematize the industry; viz., the limited partnership. This form is exemplified by the formation of Davis and Rock in 1961. These partnerships allowed VC professionals to share in the gains from startups along with the entrepreneurs and investors. Limited partnerships served to align venture capitalists' interests with those of entrepreneurs, investors, and key employees. Money was put in only at the beginning of the partnership. The general partners received management fees as a salary plus a share of the capital gains from the investments, say 40 percent, with the limited partners earning 60 percent. The limited partners had no say in the decisions of the general partners. The partnerships were structured for a limited length of time, say 7 to 10 years. The returns from the partnership were paid out to the investors only when the partnership was dissolved-there were no dividends, interest payments, etc. Therefore, the returns upon dissolution were subject only to capital gains taxation at the investor level. The VC industry also rewarded founders, CEOs, and key employees using stock options. Thus, they too were subject to capital gains taxation and not taxation on labor income. The short time horizon created pressure to ensure a venture's rapid success.

Since the life span of a VC fund is typically ten years, the venture capitalists are incentivized to target deals where a small amount of investment can generate a large financial return within a short time. Hence, VC is not the solution to creating Nobel Prize winners who advance the scientific and technological frontiers. Instead, $\mathrm{VC}$ is a promising solution for nurturing revolutionary entrepreneurs who commercialize the technological opportunities. The transistor was invented in the Bell Labs, but Intel was funded by VC. The first operational computer, the ENIAC, was invented in the University of Pennsylvania, but Ap- 
ple was funded by VC. Skilled venture capitalists are unlikely to knock on the door of the likes of Isaac Newton and Albert Einstein. Instead, they are chasing the next Steve Jobs and Elon Musk.

Banks and other financial institutions are not well suited to invest in cutting-edge new ventures. While banks are good at evaluating systematic lending risk, they have limited ability to judge the skill of entrepreneurs, the worth of new technologies, and the expertise to help commercialize them. The Glass-Steagall Banking Act of 1933 prohibited banks from taking equity positions in industrial firms-the act was repealed in 1999. Allstate Insurance Company created a private placements program in the 1960s to undertake VCtype investments. It abandoned the program because it could not compensate the VC professionals enough to retain them. The Employee Retirement Income Security Act of 1974 prevented pension funds (and dissuaded other traditional fiduciaries) from investing in high-risk ventures. The act was reinterpreted in the 1980s to allow pension funds to invest in VC-operating companies, which provided a fillip for the VC industry. The VC industry ushered in a separation between the limited partners (who have money and no operational control) and the general partners (who have expertise and operational control), which facilitated fund raising and increased efficiency.

VC activity is concentrated in three states; viz, California, Massachusetts, and New York. In 2016 these states accounted for 75 percent of VC investment and 83 percent of the assets under management. Breakthroughs in information and communications technology and biotechnology created a myriad of technological opportunities to commercialize. Numerous ventures have been founded for this purpose and they boost the demand for funding. For instance, 48 percent of $\mathrm{VC}$ investment was devoted to software companies and 11 percent for pharmaceutical and biotech companies in 2016. The high-growth startups in the hightech sectors are also geographically concentrated in these three states. Why this innovative

activity is concentrated in these three states is akin to asking why the automotive industry started in Detroit. While geographic concentration and spillovers are interesting topics to explore, they are beyond the scope of a typical growth model and, thus, are left for future research.

\section{References}

Kenney, Martin. 2011. "How Venture Capital Became a Component of the US National System of Innovation," Industrial and Corporate Change, 20 (6): 1677-1723.

Lamoreaux, Naomi, Levenstein, Margaret, and Kenneth L. Sokoloff. 2007. "Financing 
Invention during the Second Industrial Revolution: Cleveland, Ohio, 1870-1920." In Naomi Lamoreaux and Kenneth L. Sokoloff, eds., Financing Innovation in the United States, 1870 to the Present. Cambridge: The MIT Press, 39-8

\section{Theory Appendix}

Proofs for Lemmas 1 and 3 are supplied in turn here. Lemma 1 establishes the existence of a balanced-growth path. Lemma 3 shows that solving the contract problem (P2) subject to a sequence of one-shot incentive constraints is equivalent to solving it subject to a single consolidated round- 0 incentive constraint that allows for multi-shot deviations. This is proved using Lemma 2 as an intermediate step.

\subsection{Balanced Growth}

Lemma 1 (Balanced Growth) There exists a balanced-growth path of the form outlined in Section 4.3.

Proof. Suppose that $\left\{p_{t}, \sigma_{t}, \mu_{t}, \beta_{t}\right\}$ solves the old problem for $x$ and $\mathbf{x}$. It will be shown that $\left\{\mathbf{g}_{w} p_{t}, \sigma_{t}, \mu_{t}, \beta_{t}\right\}$ solves the new one for $x^{\prime}=\mathbf{g}_{\mathbf{x}} x$ and $\mathbf{x}^{\prime}=\mathbf{g}_{\mathbf{x}} \mathbf{x}$. First, observe that if $x^{\prime}=\mathbf{g}_{\mathbf{x}} x$ and $\mathbf{x}^{\prime}=\mathbf{g}_{\mathbf{x}} \mathbf{x}$, then $I\left(x^{\prime} ; \mathbf{g}_{\mathbf{x}}^{t} \mathbf{x}^{\prime}\right)=\mathbf{g}_{w} I\left(x ; \mathbf{g}_{\mathbf{x}}^{t} \mathbf{x}\right)$. This occurs because $S\left(x^{\prime} ; \mathbf{x}_{t}^{\prime}\right)=\mathbf{g}_{w} S\left(x ; \mathbf{x}_{t}\right)$. This can be seen from (P1) because $x$ will rise by $\mathbf{g}_{\mathbf{x}}$ and wages by $\mathbf{g}_{w}$. If $p_{t}^{\prime}=\mathbf{g}_{w} p_{t}$, then it is immediate from the objective function in (P2) that $C\left(x^{\prime} ; \mathbf{x}^{\prime}\right)=\mathbf{g}_{w} C(x ; \mathbf{x})$. Now, consider the incentive constraint (6). At the conjectured solution, the left-hand side will inflate by the factor $\mathbf{g}_{w}$. So will the right-hand side because $D\left(\sigma_{t}^{\prime}\right)-D\left(\widetilde{\sigma}_{t}^{\prime}\right)=\mathbf{g}_{w}\left[D\left(\sigma_{t}\right)-D\left(\widetilde{\sigma}_{t}\right)\right]$, since all costs are specified as a function of $w$. Therefore, the new solution still satisfies the incentive constraint. Move now to the zero-profit constraint (8). Again, the left-hand side will inflate by the factor $\mathbf{g}_{w}$, since $p_{t}^{\prime}=\mathbf{g}_{w} p_{t}, \phi_{t}^{\prime}=\mathbf{g}_{w} \phi_{t}, D\left(\sigma_{t}^{\prime}\right)=\mathbf{g}_{w} D\left(\sigma_{t}\right), M_{t}\left(\mu_{t}^{\prime}\right)=\mathbf{g}_{w} M_{t}\left(\mu_{t}\right)$, $E\left(\beta_{t}^{\prime}\right)=\mathbf{g}_{w} E\left(\beta_{t}\right)$, and $R\left(x^{\prime} / \mathbf{x}^{\prime}\right)=\mathbf{g}_{w} R(x / \mathbf{x})$. This is trivially true for the right-hand side. Hence, the zero-profit constraint holds at the new allocations. It is easy to deduce from the right-hand side of (6) that the old solution for $\widetilde{\sigma}_{t}$ will still hold. This can be seen by using the above argument while noting that $D_{1}\left(\widetilde{\sigma}_{t}^{\prime}\right)=\mathbf{g}_{w} D_{1}\left(\widetilde{\sigma}_{t}\right)$. To sum up, at the conjectured new solution, the objective function and the constraints all scale up by the same factor of proportionality $\mathbf{g}_{w}$. By cancelling out this factor of proportionality, the new problem reverts back to the old one. Likewise, it is easy to deduce that if $x$ solves problem (P3) for $\mathbf{x}$, then $x^{\prime}=\mathbf{g}_{\mathbf{x}} x$ solves it when $\mathbf{x}^{\prime}=\mathbf{g}_{\mathbf{x}} \mathbf{x}$. The occurs because problem (P3) also scales up by the factor of proportionality $\mathbf{g}_{w}$. When $x / \mathbf{x}$ remains constant along a balanced-growth path, then the initial research cost of the project will rise at the same rate as wages, $\mathbf{g}_{w}$. 
Additionally, $V(\mathbf{x})$ will grow the same rate as wages, $w$, so from (9) it is apparent that $\mathfrak{e}$ will remain constant.

\subsection{One-Shot Deviations versus Multi-Shot Deviations}

This is an intermediate step toward solving Lemma 3. To this end, it will be shown that if the incentive constraint (6) holds for round $t$, when the entrepreneur has not deviated up to and including round $t-1$, then it will also hold when he follows some arbitrary path of deviations up to and including round $t-1$. Let $\alpha_{t}$ represent that the probability that a project is good at round $t$ as defined by (5). These odds evolve recursively according to

$$
\alpha_{t+1}=\frac{\left(1-\widetilde{\sigma}_{t}\right) \alpha_{t}}{\left(1-\widetilde{\sigma}_{t}\right) \alpha_{t}+\left(1-\beta_{t+1}\right)\left(1-\alpha_{t}\right)},
$$

where $\alpha_{1}=\rho /\left[\rho+(1-\rho)\left(1-\beta_{1}\right)\right]$ and $\widetilde{\sigma}_{t}$ is the success probability chosen by the entrepreneur. For use in proving Lemma 2, note that $\alpha_{t+1}$ is increasing in $\alpha_{t}$ and decreasing in $\widetilde{\sigma}_{t}$. This implies that if the entrepreneur deviates in round $t$, so that $\widetilde{\sigma}_{t}<\sigma_{t}$, he will be more optimistic about the future, as $\alpha_{t+1}$ will be higher. This increases the value of the $\alpha$ 's for future rounds as well. With this notation, the round- $t$ incentive constraint (6) then reads

$$
\begin{aligned}
& \alpha_{t}(1-\tau)\left\{\delta \sigma_{t}\left[I\left(x ; \mathbf{g}_{\mathbf{x}}^{t} \mathbf{x}\right)-p_{t}\right]\right.\left.+\left(1-\sigma_{t}\right) \sum_{i=t+1}^{T} \Pi_{j=t+1}^{i-1}\left(1-\sigma_{j}\right) \delta^{i+1-t} \sigma_{i}\left[I\left(x ; \mathbf{g}_{\mathbf{x}}^{i} \mathbf{x}\right)-p_{i}\right]\right\} \\
& \geq\left(1-\mu_{t}\right) \max _{\widetilde{\sigma}_{t}}\left(D\left(\sigma_{t}\right)-D\left(\widetilde{\sigma}_{t}\right)\right. \\
&\left.+\alpha_{t}(1-\tau)\left\{\delta \widetilde{\sigma}_{t}\left[I\left(x ; \mathbf{g}_{\mathbf{x}}^{t} \mathbf{x}\right)-p_{t}\right]+\left(1-\widetilde{\sigma}_{t}\right) \sum_{i=t+1}^{T} \Pi_{j=t+1}^{i-1}\left(1-\sigma_{j}\right) \delta^{i+1-t} \sigma_{i}\left[I\left(x ; \mathbf{g}_{\mathbf{x}}^{i} \mathbf{x}\right)-p_{i}\right]\right\}\right) .
\end{aligned}
$$

Lemma 2 If the incentive constraint (6) holds for round $t$, when the entrepreneur has not deviated up to and including in round $t-1$, then it will also hold when he follows some arbitrary path of deviations up to and including in round $t-1$.

Proof. Suppose that the entrepreneur deviates in some manner before round $t$. Let $\widehat{\alpha}_{t}$ be the prior associated with this path of deviation. Since the $\widetilde{\sigma}$ 's will be less that than the $\sigma$ 's, 
it follows that $\widehat{\alpha}_{t}>\alpha_{t}$. Let $\widehat{\sigma}_{t}$ be the optimal round- $t$ deviation associated with $\widehat{\alpha}_{t}$. Now,

$$
\begin{aligned}
\alpha_{t}(1-\tau)\left\{\delta \sigma_{t}\left[I\left(x ; \mathbf{g}_{\mathbf{x}}^{t} \mathbf{x}\right)-p_{t}\right]+\right. & \left.\left(1-\sigma_{t}\right) \sum_{i=t+1}^{T} \Pi_{j=t+1}^{i-1}\left(1-\sigma_{j}\right) \delta^{i+1-t} \sigma_{i}\left[I\left(x ; \mathbf{g}_{\mathbf{x}}^{i} \mathbf{x}\right)-p_{i}\right]\right\} \\
& \geq\left(1-\mu_{t}\right)\left(D\left(\sigma_{t}\right)-D(\widehat{\sigma})\right. \\
+\alpha_{t}(1-\tau)\left\{\delta \widehat{\sigma}_{t}\left[I\left(x ; \mathbf{g}_{\mathbf{x}}^{t} \mathbf{x}\right)-p_{t}\right]\right. & \left.\left.+\left(1-\widehat{\sigma}_{t}\right) \sum_{i=t+1}^{T} \Pi_{j=t+1}^{i-1}\left(1-\sigma_{j}\right) \delta^{i+1-t} \sigma_{i}\left[I\left(x ; \mathbf{g}_{\mathbf{x}}^{i} \mathbf{x}\right)-p_{i}\right]\right\}\right),
\end{aligned}
$$

because $\widetilde{\sigma}_{t}$ is maximal when the prior is $\alpha_{t}$, while $\widehat{\sigma}_{t}$ is not. Next, replace $\alpha_{t}$ with $\widehat{\alpha}_{t}$ to get

$$
\begin{aligned}
\widehat{\alpha}_{t}(1-\tau)\left\{\delta \sigma_{t}\left[I\left(x ; \mathbf{g}_{\mathbf{x}}^{t} \mathbf{x}\right)-p_{t}\right]+\right. & \left.\left(1-\sigma_{t}\right) \sum_{i=t+1}^{T} \Pi_{j=t+1}^{i-1}\left(1-\sigma_{j}\right) \delta^{i+1-t} \sigma_{i}\left[I\left(x ; \mathbf{g}_{\mathbf{x}}^{i} \mathbf{x}\right)-p_{i}\right]\right\} \\
& \geq\left(1-\mu_{t}\right)\left(D\left(\sigma_{t}\right)-D\left(\widehat{\sigma}_{t}\right)\right. \\
+\widehat{\alpha}_{t}(1-\tau)\left\{\delta \widehat{\sigma}\left[I\left(x ; \mathbf{g}_{\mathbf{x}}^{t} \mathbf{x}\right)-p_{t}\right]\right. & \left.\left.+\left(1-\widehat{\sigma}_{t}\right) \sum_{i=t+1}^{T} \Pi_{j=t+1}^{i-1}\left(1-\sigma_{j}\right) \delta^{i+1-t} \sigma_{i}\left[I\left(x ; \mathbf{g}_{\mathbf{x}}^{i} \mathbf{x}\right)-p_{i}\right]\right\}\right),
\end{aligned}
$$

since $\widehat{\alpha}_{t}>\alpha_{t}$. Last, if the prior is $\widehat{\alpha}_{t}$, then $\widehat{\sigma}_{t}$ is maximal, so the above equation can be rewritten as

$$
\begin{gathered}
\widehat{\alpha}_{t}(1-\tau)\left\{\delta \sigma_{t}\left[I\left(x ; \mathbf{g}_{\mathbf{x}}^{t} \mathbf{x}\right)-p_{t}\right]+\left(1-\sigma_{t}\right) \sum_{i=t+1}^{T} \Pi_{j=t+1}^{i-1}\left(1-\sigma_{j}\right) \delta^{i+1-t} \sigma_{i}\left[I\left(x ; \mathbf{g}_{\mathbf{x}}^{i} \mathbf{x}\right)-p_{i}\right]\right\} \\
\geq\left(1-\mu_{t}\right) \max _{\widehat{\sigma}_{t}}\left(D\left(\sigma_{t}\right)-D\left(\widehat{\sigma}_{t}\right)\right. \\
\left.+\widehat{\alpha}_{t}(1-\tau)\left\{\delta \widehat{\sigma}_{t}\left[I\left(x ; \mathbf{g}_{\mathbf{x}}^{t} \mathbf{x}\right)-p_{t}\right]+\left(1-\widehat{\sigma}_{t}\right) \sum_{i=t+1}^{T} \Pi_{j=t+1}^{i-1}\left(1-\sigma_{j}\right) \delta^{i+1-t} \sigma_{i}\left[I\left(x ; \mathbf{g}_{\mathbf{x}}^{i} \mathbf{x}\right)-p_{i}\right]\right\}\right) .
\end{gathered}
$$

Hence the round- $t$ incentive constraint hold when for some arbitrary path of deviations up to and including in round $t-1$. 


\subsection{The Consolidated Round-0 Incentive Constraint}

The consolidated round-0 incentive constraint is

$$
\begin{aligned}
& (1-\tau) \sum_{t=1}^{T} \rho \Pi_{j=1}^{t-1}\left(1-\sigma_{j}\right) \delta^{t} \sigma_{t}\left[I\left(x ; \mathbf{g}_{\mathbf{x}}^{t} \mathbf{x}\right)-p_{t}\right] \\
& \geq \max _{\left\{\widetilde{\sigma}_{t}\right\}_{t=1}^{T}}\left\{\sum_{t=1}^{T} \delta^{t-1}\left[\rho \Pi_{j=1}^{t-1}\left(1-\widetilde{\sigma}_{j}\right)+(1-\rho) \Pi_{j=1}^{t}\left(1-\beta_{j}\right)\right]\right. \\
& \times\left(1-\mu_{t}\right)\left[D\left(\sigma_{t}\right)-D\left(\widetilde{\sigma}_{t}\right)\right] \\
& \left.+(1-\tau) \sum_{t=1}^{T} \rho \Pi_{j=1}^{t-1}\left(1-\widetilde{\sigma}_{j}\right) \delta^{t} \widetilde{\sigma}_{t}\left[I\left(x ; \mathbf{g}_{\mathbf{x}}^{t} \mathbf{x}\right)-p_{t}\right]\right\} .
\end{aligned}
$$

Lemma 3 (Equivalence of contracts) A contract $\left\{\beta_{t}, \sigma_{t}, \mu_{t}, p_{t}\right\}$ solves problem (P2) subject to the sequence of one-shot incentive constraints (6) if and only if it solves (P2) subject to the consolidated round-0 incentive constraint (20).

Proof (by contradiction). (Necessity) Suppose that an allocation satisfies the one-shot incentive compatibility constraints (6) but that it violates the consolidated one (20). This implies that at some round in the problem with the consolidated constraint it pays to deviate and pick a $\widetilde{\sigma}_{t} \neq \sigma_{t}$. Pick the last round of deviation (which may be $T$ ). It must be true that $\tilde{\sigma}_{t}$ solves the maximization problem

$$
\begin{aligned}
& \left(1-\mu_{t}\right) \max _{\widetilde{\sigma}_{t}}\left(D\left(\sigma_{t}\right)-D\left(\widetilde{\sigma}_{t}\right)\right. \\
& \left.+\widehat{\alpha}_{t}(1-\tau)\left\{\delta \widetilde{\sigma}_{t}\left[I\left(x ; \mathbf{g}_{\mathbf{x}}^{t} \mathbf{x}\right)-p_{t}\right]+\left(1-\widetilde{\sigma}_{t}\right) \sum_{i=t+1}^{T} \Pi_{j=t+1}^{i-1}\left(1-\sigma_{j}\right) \delta^{i+1-t} \sigma_{i}\left[I\left(x ; \mathbf{g}_{\mathbf{x}}^{i} \mathbf{x}\right)-p_{i}\right]\right\}\right)
\end{aligned}
$$

where $\widehat{\alpha}_{t}$ is the prior associated with the path of $\sigma$ 's up to round $t-1$, which may include previous deviations. But, from Lemma 2, this is less than the value of sticking with the contract or

$$
\widehat{\alpha}_{t}(1-\tau)\left\{\delta \sigma_{t}\left[I\left(x ; \mathbf{g}_{\mathbf{x}}^{t} \mathbf{x}\right)-p_{t}\right]+\left(1-\sigma_{t}\right) \sum_{i=t+1}^{T} \Pi_{j=t+1}^{i-1}\left(1-\sigma_{j}\right) \delta^{i+1-t} \sigma_{i}\left[I\left(x ; \mathbf{g}_{\mathbf{x}}^{i} \mathbf{x}\right)-p_{i}\right]\right\}
$$


when the round- $t$ one-shot incentive constraint (6) holds, as assumed. Thus, a contradiction emerges.

(Sufficiency) Suppose $\left\{\sigma_{t}\right\}_{t=1}^{T}$ satisfies the consolidated incentive constraint, but violates the one-shot incentive constraint at round $k$. Then, using (5) and (6), it follows that

$$
\begin{gathered}
\rho \Pi_{j=1}^{k-1}\left(1-\sigma_{j}\right) \delta^{k-1}(1-\tau)\left\{\delta \sigma_{k}\left[I\left(x ; \mathbf{g}_{\mathbf{x}}^{k} \mathbf{x}\right)-p_{k}\right]+\left(1-\sigma_{k}\right) \sum_{t=k+1}^{T} \Pi_{j=k+1}^{t-1}\left(1-\sigma_{j}\right) \delta^{t+1-k} \sigma_{t}\left[I\left(x ; \mathbf{g}_{\mathbf{x}}^{t} \mathbf{x}\right)-p_{t}\right]\right\} \\
=(1-\tau) \sum_{t=k}^{T} \rho \Pi_{j=1}^{t-1}\left(1-\sigma_{j}\right) \delta^{t} \sigma_{t}\left[I\left(x ; \mathbf{g}_{\mathbf{x}}^{t} \mathbf{x}\right)-p_{t}\right] \\
<\delta^{k-1}\left(1-\mu_{k}\right)\left(\left[\rho \Pi_{j=1}^{k-1}\left(1-\sigma_{j}\right)+(1-\rho) \Pi_{j=1}^{k}\left(1-\beta_{j}\right)\right]\left[D\left(\sigma_{k}\right)-D\left(\widetilde{\sigma}_{k}\right)\right]\right. \\
\left.+\rho \Pi_{j=1}^{k-1}\left(1-\sigma_{j}\right)(1-\tau)\left\{\delta \widetilde{\sigma}_{k}\left[I\left(x ; \mathbf{g}_{\mathbf{x}}^{k} \mathbf{x}\right)-p_{k}\right]+\left(1-\widetilde{\sigma}_{k}\right) \sum_{t=k+1}^{T} \prod_{j=k+1}^{t-1}\left(1-\sigma_{j}\right) \delta^{t+1-k} \sigma_{t}\left[I\left(x ; \mathbf{g}_{\mathbf{x}}^{t} \mathbf{x}\right)-p_{t}\right]\right\}\right) .
\end{gathered}
$$

The left-hand side gives the payoff in the contract at the optimal solution from round $k$ on, when using the consolidated incentive constraint, while the right-hand side represents the payoff from a one-shot deviation at round $k$.

Now the objective function for the contract can be written as

$$
(1-\tau) \sum_{t=1}^{k-1} \rho \Pi_{j=1}^{t-1}\left(1-\sigma_{j}\right) \delta^{t} \sigma_{t}\left[I\left(x ; \mathbf{g}_{\mathbf{x}}^{t} \mathbf{x}\right)-p_{t}\right]+(1-\tau) \sum_{t=k}^{T} \rho \Pi_{j=1}^{t-1}\left(1-\sigma_{j}\right) \delta^{t} \sigma_{t}\left[I\left(x ; \mathbf{g}_{\mathbf{x}}^{t} \mathbf{x}\right)-p_{t}\right] .
$$

Evaluate this at the optimal solution for the contract when using (20) instead of (6). Next, in this objective function, replace the payoff from round $k$ on, as represented by the left-hand side of (21), with the payoff from the one-shot deviation as given by the right-hand side. This deviation increases the value of the objective function for the entrepreneur under the contract with the time-0 incentive constraint, which contradicts its optimality. 